\title{
Recent Advances on Design and Synthesis of Chiral Imidazolium Ionic Liquids and their Applications in Green Asymmetric Synthesis
}

\author{
Arijit Saha, Soumen Payra and Subhash Banerjee*
}

\author{
Department of Chemistry, Guru Ghasidas Vishwavidyalaya (A Central University), Bilaspur -495009 (C.G.), \\ India
}

\begin{abstract}
Over the past decade, catalysis by ionic liquids (ILs) has experienced a tremendous growth in the context of "Green Chemistry", and there are numerous examples of a variety of catalytic reactions that have been successfully carried out in such neoteric media. The great enthusiasm for catalysis in ILs is not only driven by the curiosity of chemists, but also due to the growing awareness of developing greener reactions or process media in catalytic science and greener catalytic technologies due their advantages of unique physical and chemical properties as compared to traditional volatile organic solvents. Recently, development of chiral ionic liquids and their applications in asymmetric synthesis have attracted much attention as these reactions have widespread applications in the synthesis of chiral drugs and pharmaceutical industries. Asymmetric induction is mainly achieved by the use of chiral substrates or reagents, chiral catalysts or enzymes. Owing to the vast number of structurally different room temperature ILS that have been synthesized, this review focuses on imidazolium ionic liquids that possess chirality either in the imidazolium moiety or in the anion moiety. The aim of this review is to highlight the recent breakthrough of Chiral ILs in chirality transfer or chiral recognition when used as solvent or co-solvent: the case of task specific ionic liquids is beyond the scope of this review. In the first part, the synthesis of of CILs has been presented and the second part of the review has been devoted on the applications of such CILs in green asymmetric synthesis as well as various pharmaceutical industries.
\end{abstract}

Keywords: Chiral Imidazolium lonic Liquids, Chiral Catalyst and Reaction Medium, Green Asymmetric Synthesis, Recyclable Homogeneous Catalyst, Solvent-free Clean Synthesis.

\section{INTRODUCTION}

lonic liquids (ILs) often recognized as molten salts having melting point below $100{ }^{\circ} \mathrm{C}$ with entirely ionic character, consisting of both a cationic and anionic parts (Figure 1) [1].

ILs usually consists of several properties such as low melting organic salts $\left(<100{ }^{\circ} \mathrm{C}\right)$, very low vapor pressure, non-flammable, wide liquid range, moderate to high viscosity, high thermal/mechanical/ electrochemical stability, low toxicity, high Solvating properties etc. Interestingly, physical and chemical properties can be tailored by the modification of cationic and anionic core, hence for this structural diversity ILs are generally termed as designer solvent [2]. The first report of ILs emerged in 1914 [3]; since then, it has been taken tremendous attention in the perspective of green Synthesis for their unique, diverse and tunable properties. There are varieties of examples of catalytic reactions that have been efficiently promoted in presence of such materials as the catalyst and/or reaction media [4]. Now, introduction of chiral building blocks in either in the cationic part or in the anion moiety of ILs make it novel materials because of

*Address correspondence to this author at the Department of Chemistry, Guru Ghasidas Vishwavidyalaya (A Central University), Bilaspur -495009 (C.G.), India; Tel: 91-7587401979; Fax: 07752-260148; E-mail: ocsb2006@gmail.com, ocas2011@yahoo.com, payrasoumen@gmail.com its promising efficacy as asymmetric catalyst for the fabrication of chiral drugs and biomolecules. Several examples of asymmetric induction by chiral ionic liquids (CILs) have been reported in the literature [5].

Recently, asymmetric catalysis by imidazolium based CILs have concerned much interest predominantly in pharmaceutical industries. This growing interest in the exploitation of CILs for chiral induction has provoked us to commence the review on imidazolium based CILs and their applications in green asymmetric synthesis. The present study focuses on recent advances on design and synthesis of imidazolium based CILs and highlights their applications in green asymmetric synthesis.

\section{DEVELOPMENT OF CHIRAL IMIDAZOLIUM IONIC LIQUIDS AND THEIR APPLICATIONS IN GREEN ASYMMETRIC SYNTHESIS}

\subsection{Chiral Imidazolium Ionic Liquids with Chiral Anions}

In 1999, chiral imidazolium ionic liquid was invented by Seddon and co-workers [6]. They prepared chiral 1$n$-butyl-3-methylimidazolium L-lactate ([bmim][lactate]), 1, simply by introducing $(S)$-2-hydroxypropionate as the chiral anion (Scheme 1).

Ohno et al. have fabricated a number of bio-based chiral imidazolium ionic liquids, 2, derived from chiral 


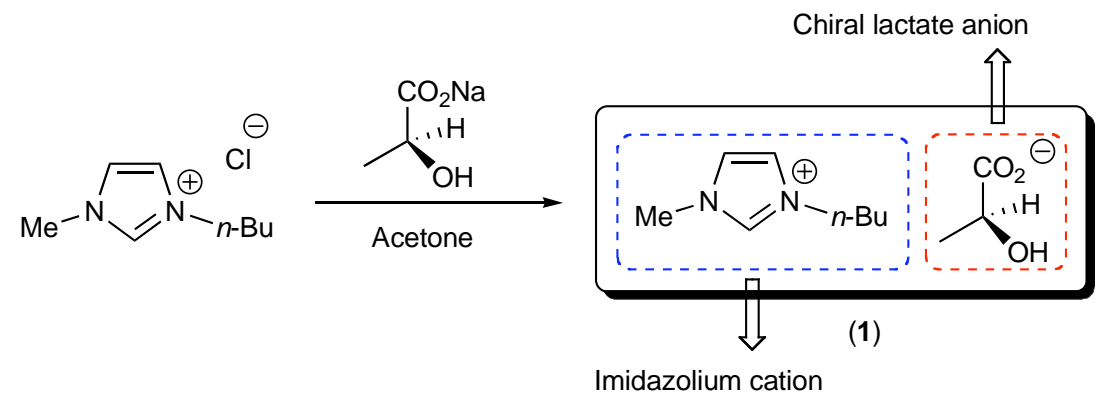

Scheme 1: First report for the synthesis of imidazolium based CIILs.

amino acids via anion exchange techniques (Figure 1) [7].

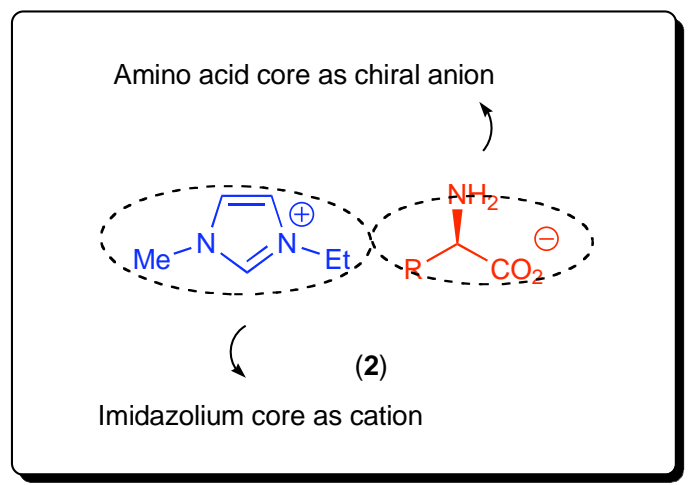

Figure 1: Naturally occurring amino acids derived imidazolium CILs.

The conversion of 1-ethyl-3-methylimidazolium bromide ([emim] $[\mathrm{Br}])$ into 1-ethyl-3-methylimidazolium hydroxide ([emim][OH]) using an anion-exchange resin, subsequently, neutralization of $([\mathrm{emim}][\mathrm{OH}]$ with a series of amino acids provide the desired CILs, 2, as the transparent and almost colorless liquids at room temperature (Scheme 2). The as prepared CILs except [emim][Glu] and [emim][Asp] (both contain two carboxyl groups) are miscible in different organic solvents such as methanol, acetonitrile, and chloroform etc. Only [emim][Cys] shows thermal stability up to $173{ }^{\circ} \mathrm{C}$ and all the other CILs exhibit good thermal stability $(>200$ $\left.{ }^{\circ} \mathrm{C}\right)$. The effects of different side chains in amino acid residues of the CILs on glass transition temperature $(T g)$ have also been investigated. The increase in the length of the alkyl side chain of the amino acid cores in the CILs results gradual increase in $\mathrm{Tg}$, which was associated to the increase in the van der Waals attraction between the alkyl groups (Scheme 2).

Recently, Ohno et al. synthesized another new imidazolium CIILs containing amino acids modified chiral anions (Scheme 3) [8]. The synthesis of these<smiles></smiles>

\begin{tabular}{ccc}
\hline $\begin{array}{c}\text { Anionic part } \\
\text { of } \mathbf{1}\end{array}$ & $\begin{array}{c}\mathrm{T}_{\mathrm{g}}\left({ }^{\circ} \mathrm{C}\right) \\
\text { of } \mathbf{1}\end{array}$ & $\begin{array}{c}\text { Yield (\%) } \\
\text { of } \mathbf{1}\end{array}$ \\
\hline Gly & -62 & 82 \\
Ala & -57 & 86 \\
Met & -57 & 78 \\
Val & -52 & 79 \\
Ile & -52 & 82 \\
Leu & -51 & 80 \\
Ser & -49 & 79 \\
Pro & -48 & 83 \\
Lys & -47 & 78 \\
Thr & -40 & 84 \\
\hline
\end{tabular}

\begin{tabular}{|ccc}
\hline $\begin{array}{c}\text { Anionic part } \\
\text { in } \mathbf{1}\end{array}$ & $\begin{array}{r}\mathrm{T}_{\mathrm{g}}\left({ }^{\circ} \mathrm{C}\right) \\
\text { of } \mathbf{1}\end{array}$ & $\begin{array}{c}\text { Yield (\%) } \\
\text { of } \mathbf{1}\end{array}$ \\
\hline Phe & -36 & 83 \\
Trp & -31 & 82 \\
His & -24 & 78 \\
Tyr & -23 & 70 \\
Cys & -19 & 77 \\
Arg & -18 & 74 \\
Asn & -16 & 83 \\
Gln & -12 & 66 \\
Asp & 5 & 79 \\
Glu & 6 & 80 \\
\end{tabular}

Scheme 2: Synthesis of bio-based chiral imidazolium ionic liquids. 


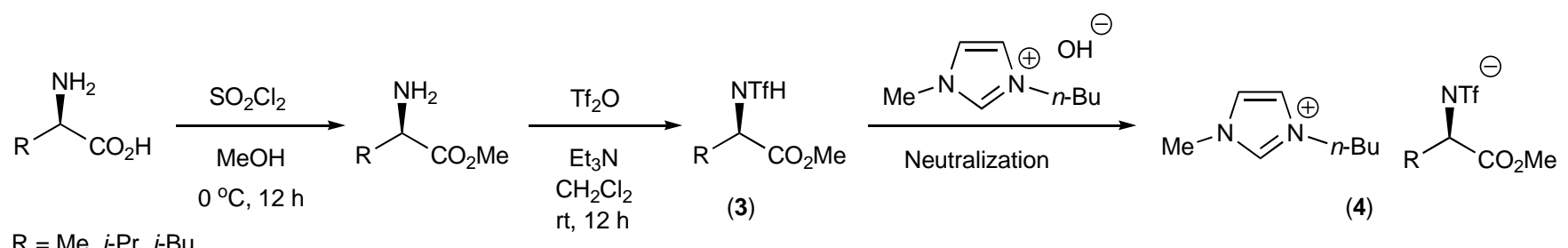

Scheme 3: Synthesis of amino acids modified imidazolium based CIILs.

CILs involves three steps. Amino acids were converted to corresponding methyl esters by the treatment of thionyl chloride in methanol at $0{ }^{\circ} \mathrm{C}$, subsequently, reaction with trifluoromethanesulfonic anhydride in presence of triethylamine in dichloromethane produced methyl esters of $\mathrm{N}$-trifluoromethanesulfonylamino acid analogous (3). Finally, neutralization of $[\mathrm{bmim}][\mathrm{OH}]$ with the ester (3) afforded the desired CIILs (4).

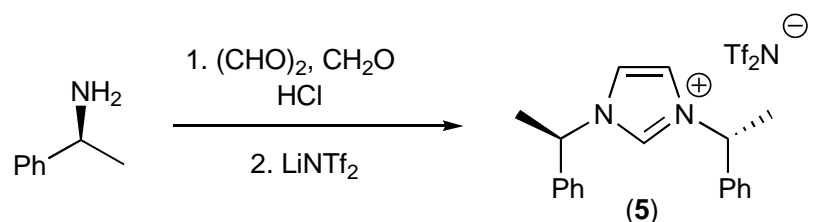

Scheme 4: CILs containing two chiral centers attached to imidazole core.

\subsection{Chiral Imidazolium Ionic Liquids with Chiral Cations:}

Ding et al. have synthesized imidazolium based chiral ionic liquid (5) containing chiral imidazolium moiety bearing two chiral centers bonded to a nitrogen atoms of the imidazole centre (Scheme 4) [9].

Bao et al. synthesized of same type of chiral imidazolium ionic liquid (6) with single chiral center derived from the $(R)-(+)$ - $\alpha$-methylbenzylamine (Scheme 5) [10]. This ionic liquid failed to promote asymmetric reactions due to its high melting point $\left(90^{\circ} \mathrm{C}\right)$.

Also, Bao and co-workers have synthesized new imidazolium CILs containing chiral imidazolium moiety as cation modified by amino acids (Scheme 6) [10]. Chiral imidazolium ring (5) was synthesized by four component reaction of amino acid, formaldehyde, glyoxal and ammonia under basic condition. Then, the acid functional groups of amino acids were converted into corresponding ethyl esters (7). The ethyl esters (7) upon treatment with lithium aluminum hydride $\left(\mathrm{LiAlH}_{4}\right)$ produced corresponding ethyl alcohol analogous followed by the reaction with bromoethane gave desired CILs (8).

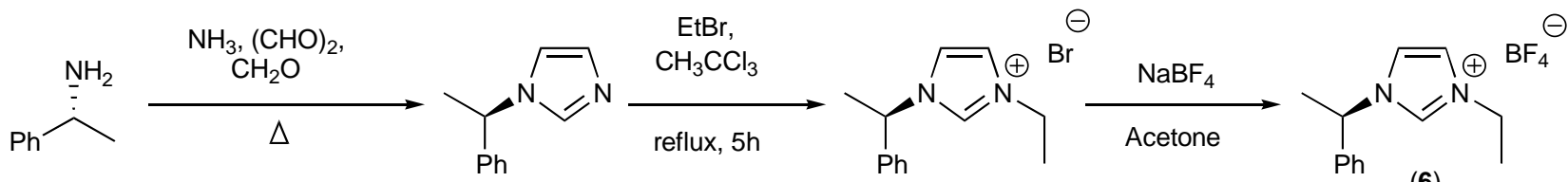

Scheme 5: Synthesis of single chiral imidazolium moiety derived CILs.

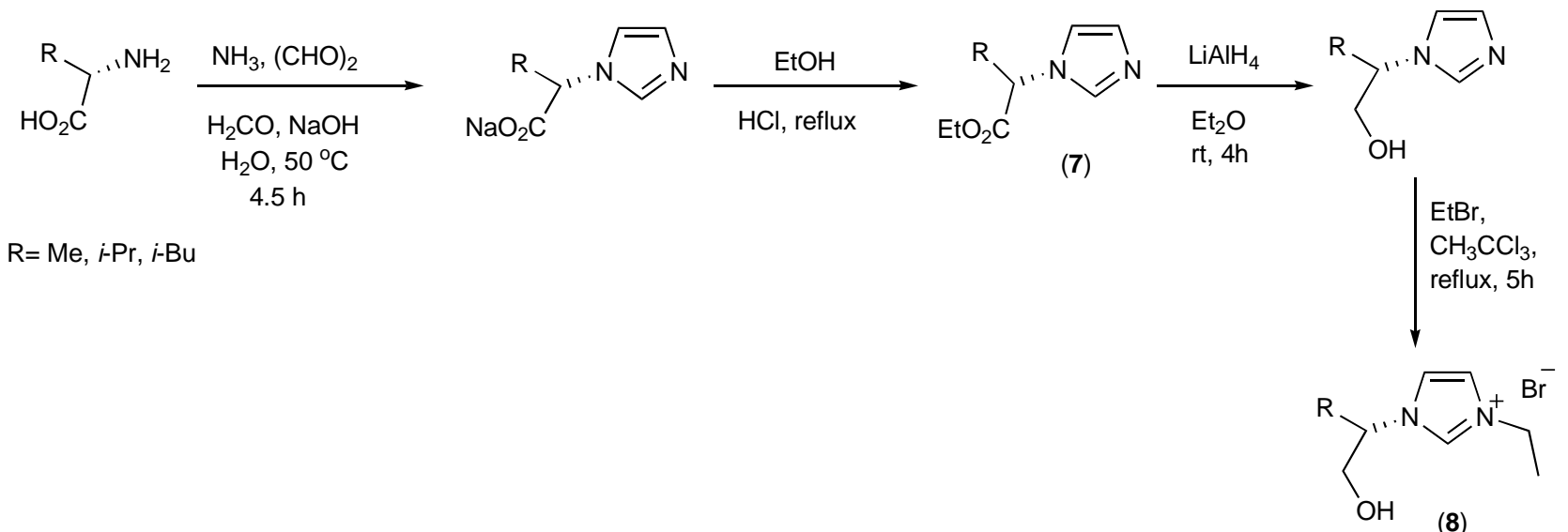

Scheme 6: CILs containing amino acid modified chiral imidazolium cation. 


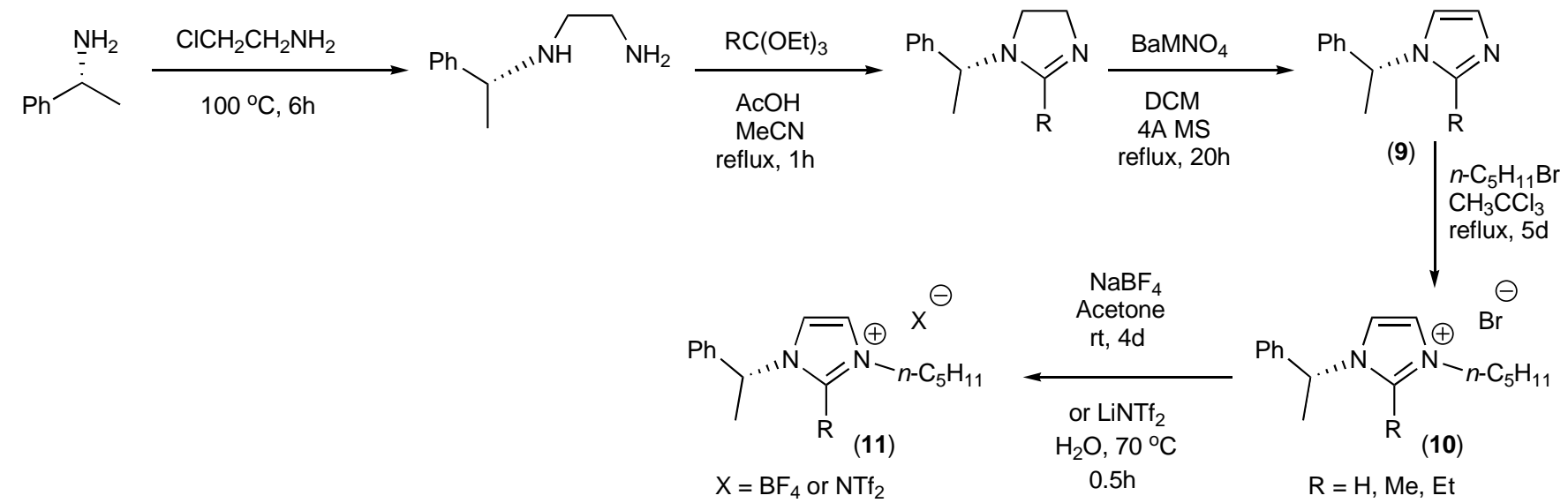

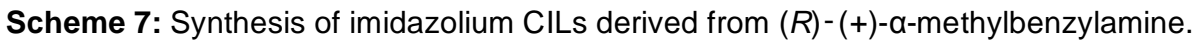

Recently, Génisson et al. have synthesized a new series of novel chiral imidazolium ionic liquids starting from $(R)-(+)$-a-methylbenzylamine [11]. First they have prepared chiral imidazole moiety (7) via alkylation of $(R)-(+)$ - $\alpha$-methylbenzylamine with chloroethylamine followed by the treatment with ortho ester and barium permanganate. Subsequently, compound, 9, was treated with $n$-pentyl bromide giving CILs, 10, which was then converted to desire CILs, 11, via anion exchange with $\mathrm{NaBF}_{4}$ or $\mathrm{LiNTf}_{2}$ (Scheme 7).

Kim et al. have prepared a new type of chiral imidazolim ionic liquids (12) derived from chiral alcohols (S)-2-hexanol and (R)-a-methylbenzyl alcohol via Mitsunobu alkylation of imidazole moiety (Scheme 8) [12].

Machado et al. have synthesized another new imidazolium CIL (13) starting form (1S,2S,5S)-(-)myrtanol (Scheme 9) [13].
Tosoni et al. have been synthesized chiral citronellol moiety containing imidazolium based CIILs (16) [14]. They have prepared CIL, 16, starting from the bromination of $(3 R)$-citronellol with $\mathrm{Br}_{2}$ and $\mathrm{PPh}_{3}$ in $\mathrm{CH}_{2} \mathrm{Cl}_{2}$ at room temperature to produce corresponding citronellyl bromide derivative (14) which on heating 1 alkyl-1H-imidazoles for few days gave chiral imidazolium bromide salts (15). Subsequently, anion exchange with $\mathrm{NaBF}_{4}$ in acetone, led to the corresponding imidazolium tetrafluoroborates as CILs (Scheme 10). In addition, they have also prepared 1,3dicitronellyl- $1 \mathrm{H}$-imidazolium bromide by deprotonation of $1 \mathrm{H}$-imidazole (17) with $(n-\mathrm{Bu})_{4} \mathrm{NOH}$ and subsequent treatment with 2 equivalents of the chiral bromide (Scheme 10).

Xu et al. prepared chiral amino acids functionalized chiral imidazolium ionic liquids [15]. First, amino acids were reduced to amino alcohols by $\mathrm{NaBH}_{4} / l_{2}$, followed by neutralized and under goes bromonation with $\mathrm{PBr}_{3}$.

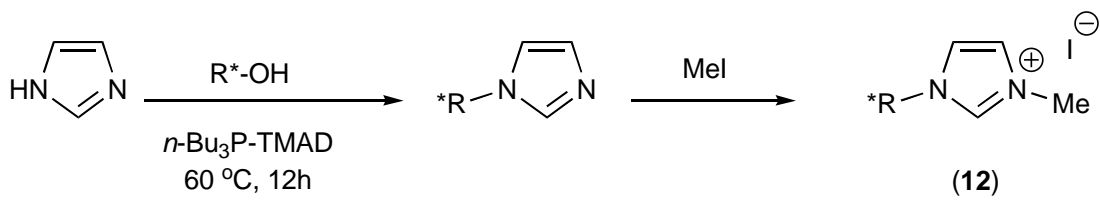

$\mathrm{R}^{*}-\mathrm{OH}=\overbrace{\mathrm{OH}}^{\text {and }} \overbrace{\mathrm{Ph}}^{s^{5}}$

Scheme 8: Synthesis of chiral imidazolium chiral ionic liquids derived form chiral alcohol.

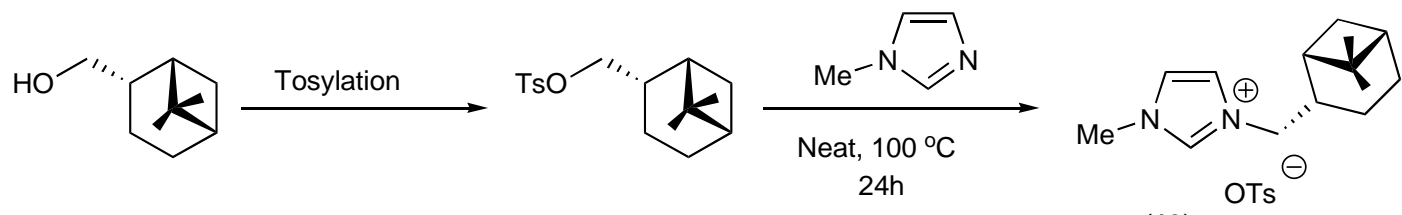

(13)

Scheme 9: Synthesis of chiral imidazolium based CILs derived form chiral myrtanol. 


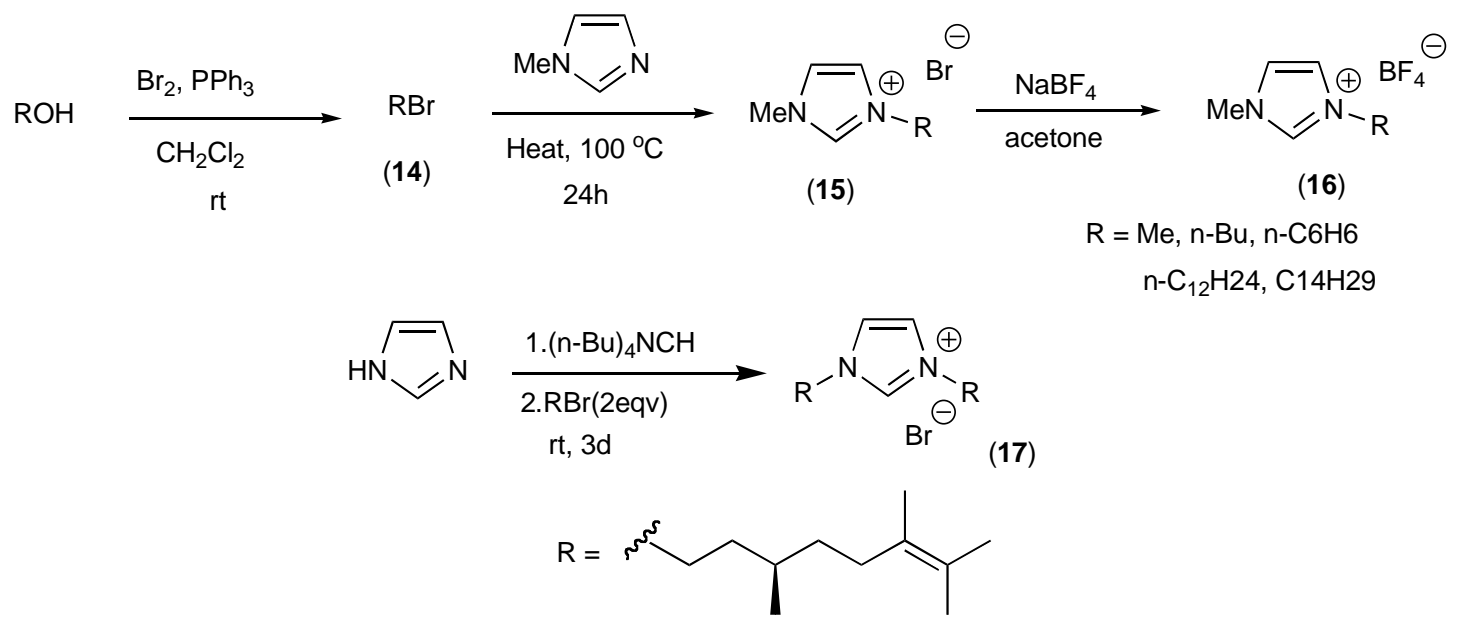

Scheme 10: Synthesis of chiral imidazolium CILs derived form chiral citronellol.

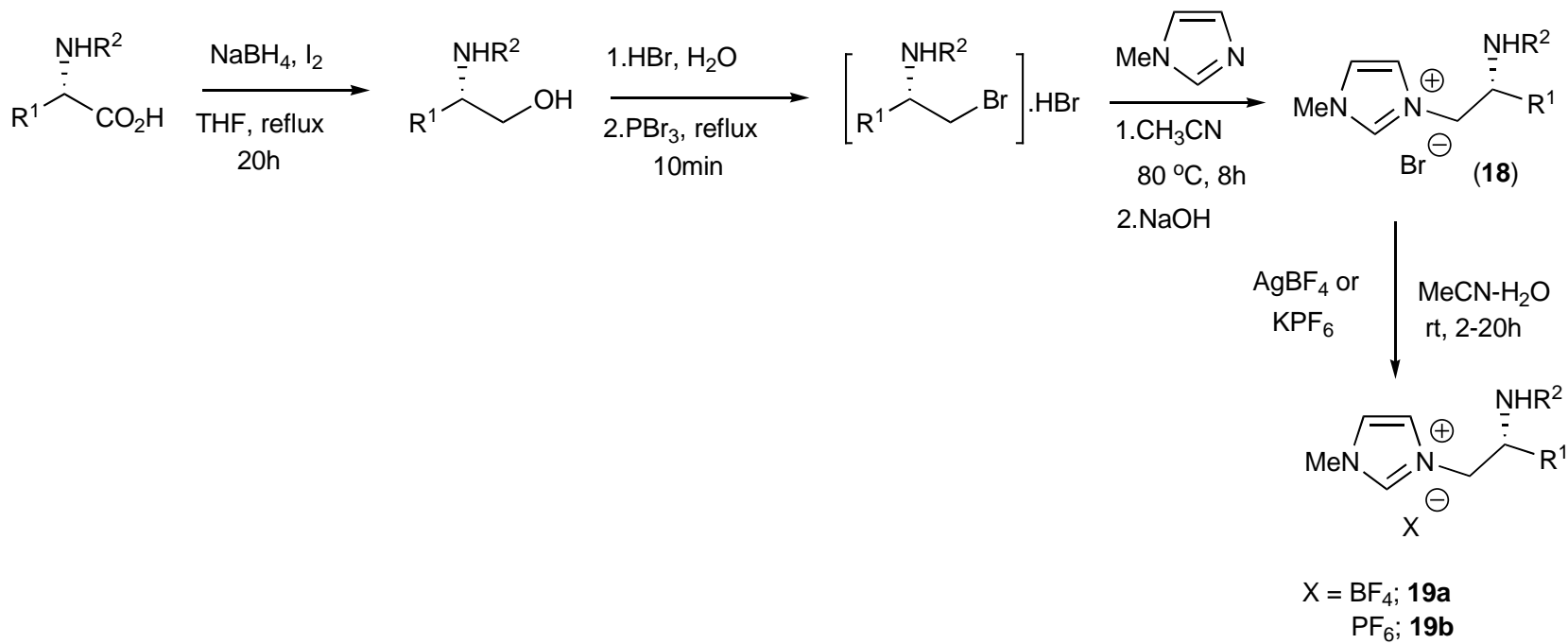

Scheme 11: Synthesis of chiral imidazolium CILs derived from amino acids.

Then, $\mathrm{N}$-alkylation with methylimidazole followed by neutralization with $\mathrm{NaOH}$ gave chiral imidazolium bromide salts (18). Anion exchange of 18 with $\mathrm{AgBF}_{4}$ or $\mathrm{KPF}_{6}$ produced the desired CILs (19a and 19b) with thermal stability up to $210{ }^{\circ} \mathrm{C}$ (Scheme 11). The as prepared CILs, 19b, exhibit higher melting points and glass-transition temperatures than the CILs, 19a.

Recently, Ni et al. synthesized new novel CIILs, 20, from chiral amino alcohols (Scheme 12) [16].

$\mathrm{Ou}$ and Huang developed a useful method for synthesizing imidazolium ILs from amino alcohols [17]. The reaction of 1-(2,4-dinitrophenyl)-3-methylimidazolium chloride with chiral primary amino alcohols gave CILs followed by, anionexchange with fluoroboric acid or potassiumhexafluorophosphate produced the CIILs, 21a-c and 22a-c (Scheme 13).
Luo et al. synthesized pyrrolidine modified imidazolium CIILs starting from L-proline (Scheme 14) [18].

Miao et al. [19] have synthesized proline moiety containing imidazolium CIILs (27 and 30) (Scheme 15).

Guillen et al. have synthesized histidine functionalized imidazolium chiral ionic liquids 32 [20]. Protection of histidine methyl ester, followed by alkylation with iodomethane and oxidative ring opening of the cyclic urea by $t-\mathrm{BuOOH}$ in the presence of $(i-\operatorname{Pr})_{2} \mathrm{NEt}$, resulting histidine derivative, 31. After that, the reaction of 31 , with $n$-butylbromide, followed by anion exchange resulting desired histidine functionalized imidazolium CIL (Scheme 16).

$\mathrm{Ni}$ et al. have synthesized a new pyrrolidine based CIILfrom L-proline (35) [21]. The reaction of 3chloropropanesulfonyl chloride with (S)-2-aminomethyl- 

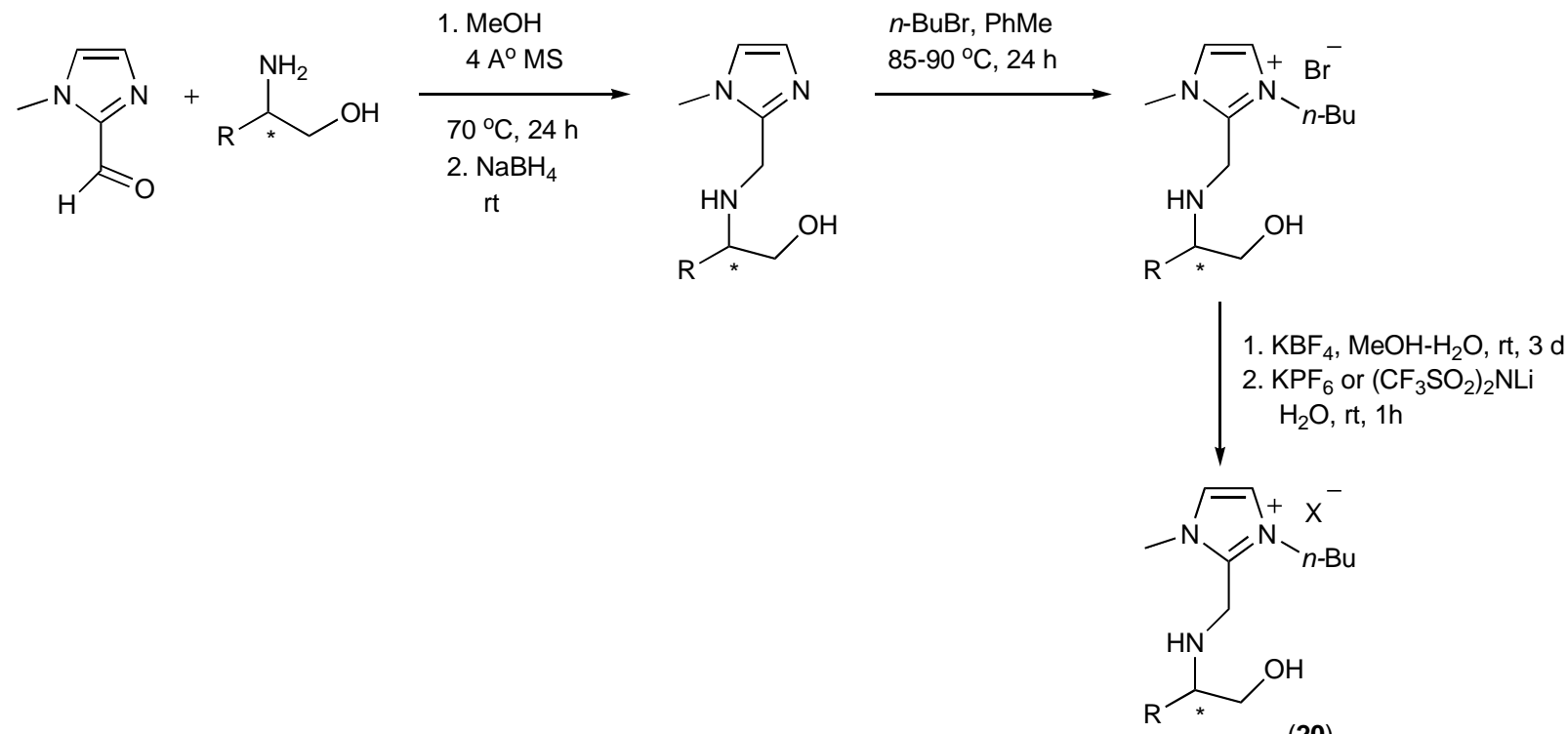

$\mathrm{R}=i-\mathrm{Pr}, i-\mathrm{Bu}, \mathrm{Bn}$ $\mathrm{X}=\mathrm{BF}_{4}, \mathrm{PF}_{6}, \mathrm{NTf}_{2}$

Scheme 12: Synthesis of imidazolium CIILs from amino alcohol.
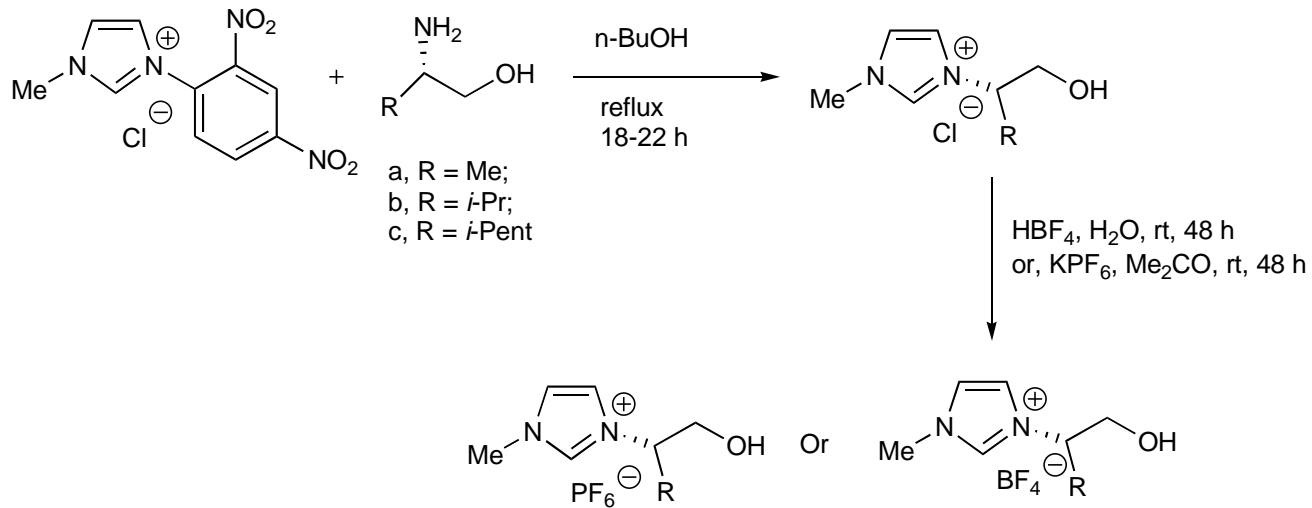

$$
\text { (22 a-c) (21 a-c) }
$$

Scheme 13: Synthesis of CIILs from chiral amino alcohols.

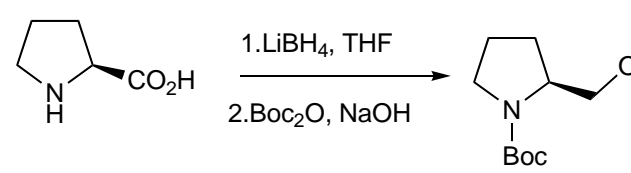

$83 \%$<smiles>CC(C)(C)OC(=O)N1CCC[C@H]1Cn1ccnc1</smiles>

$90 \%$

(23)

$$
\begin{gathered}
\text { n-BuBr } \\
\text { PhMe, } 80^{\circ} \mathrm{C}
\end{gathered}
$$

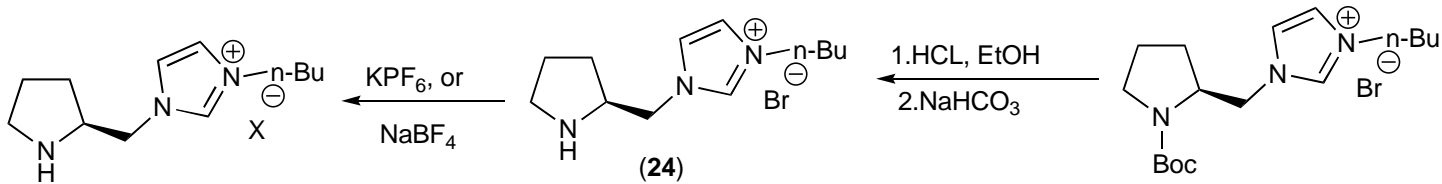

$$
\begin{array}{r}
\mathrm{X}=\mathrm{BF}_{4} ; \mathbf{2 5 a} \\
\mathrm{PF}_{6} ; \mathbf{2 5 b}
\end{array}
$$

Scheme 14: Synthesis of imidazolium CIILs starting from amino acid. 


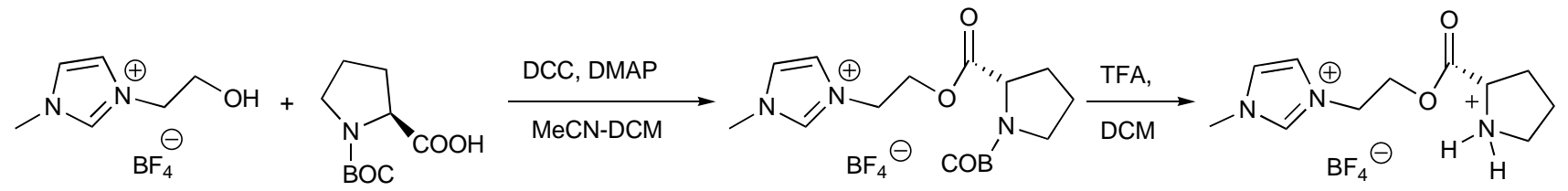

(26)

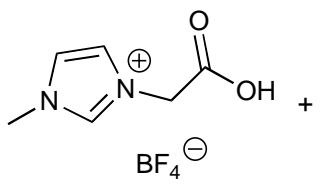

(28)

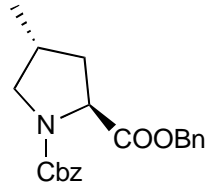

$\mathrm{Cbz}$

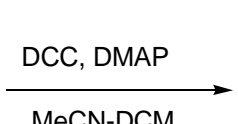

MeCN-DCM<smiles>Cn1cc[n+](CC(=O)O)c1</smiles>

(29)<smiles></smiles>
$\mathrm{BF}_{4} \ominus$<smiles>O=C(O)[C@@H]1CCCN1</smiles>

Scheme 15: Synthesis of imidazolium CILs starting from L-Proline derivatives.

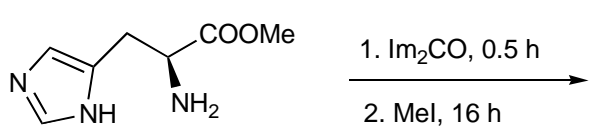<smiles></smiles><smiles>CC(C)(C)O[Mg]O[Se]</smiles><smiles>COC(=O)C(Cc1cn(C)cn1)NC(=O)O</smiles>

1. $\mathrm{n}-\mathrm{BuBr}$, heat 2. $\mathrm{LiNTF}_{2}$ or $\mathrm{KPf}_{6}$ or $\mathrm{NaBF}_{4}$

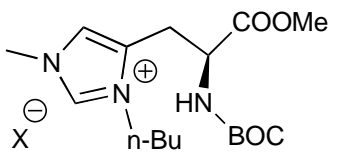

(32) $\mathrm{BF}_{4}$

Scheme 16: Synthesis of histidine functionalized imidazolium CIL.

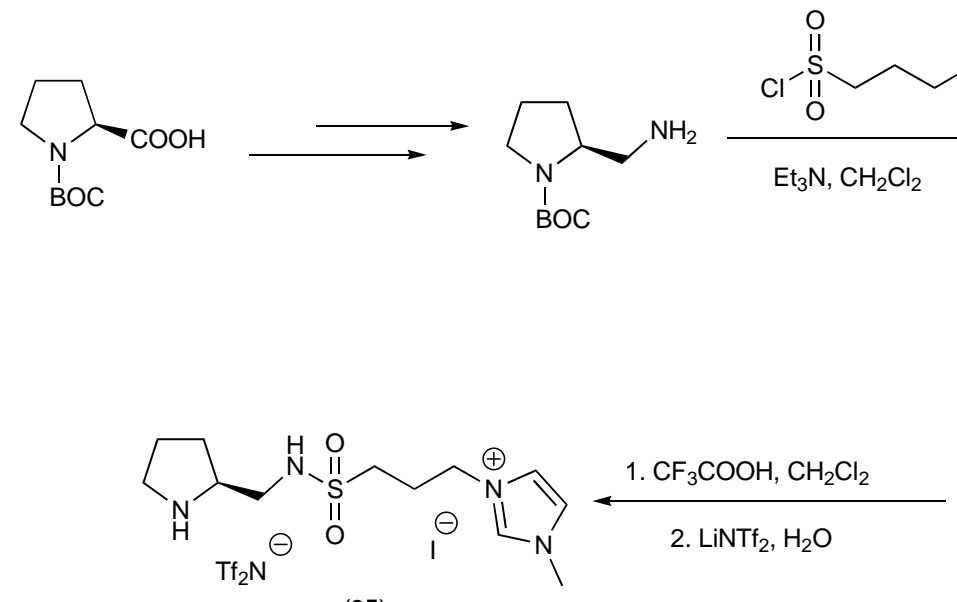

(35)<smiles>Cn1cc[n+](CCCS(=O)(=O)NC[C@H]2CCCN2C(=O)OC(C)(C)C)c1</smiles>

(34)

Scheme 17: Synthesis of Pyrrolidine-Based CIILs from I-Proline. 

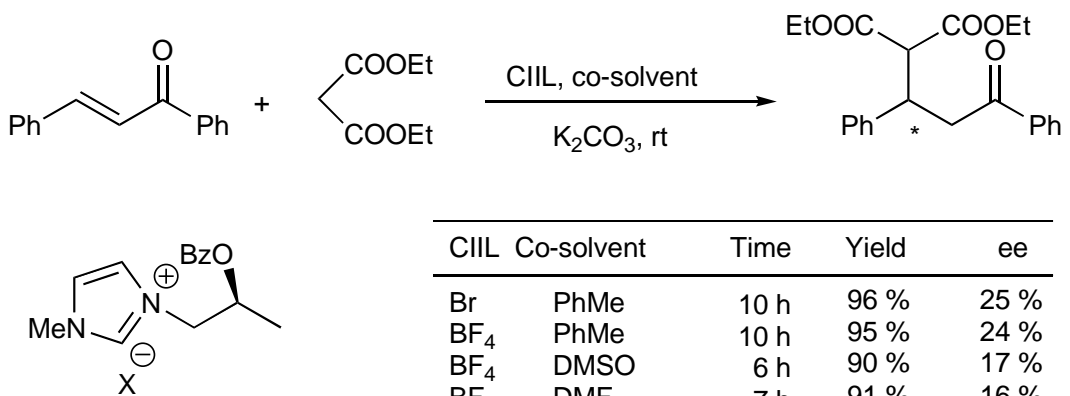

\begin{tabular}{lcrcc}
\hline CIIL & Co-solvent & Time & Yield & ee \\
\hline $\mathrm{Br}$ & PhMe & $10 \mathrm{~h}$ & $96 \%$ & $25 \%$ \\
$\mathrm{BF}_{4}$ & $\mathrm{PhMe}$ & $10 \mathrm{~h}$ & $95 \%$ & $24 \%$ \\
$\mathrm{BF}_{4}$ & $\mathrm{DMSO}$ & $6 \mathrm{~h}$ & $90 \%$ & $17 \%$ \\
$\mathrm{BF}_{4}$ & $\mathrm{DMF}$ & $7 \mathrm{~h}$ & $91 \%$ & $16 \%$ \\
$\mathrm{PF}_{6}$ & $\mathrm{PhMe}$ & $10 \mathrm{~h}$ & $93 \%$ & $23 \%$
\end{tabular}

$\mathrm{X}=\mathrm{Br}$ or $\mathrm{BF}_{4}$ orPF

Scheme 18: Imidazolium CIL as solvent in asymmetric Michael addition.

1-Boc-pyrrolidine obtained from L-proline, gave sulfonamide (33). Conversion of $\mathbf{3 3}$ into imidazolium iodide was done by iodination with $\mathrm{Nal}$ followed by alkylation producing CIL, 34. After that, BOC deprotection and subsequently, anion exchange with $\mathrm{Tf}_{2} \mathrm{~N}^{-}$resulting the desired CIIL, 35 .

\subsection{Applications of CIILs in Asymmetric Organic Reactions}

In 1975, Seebach and Oei first applied chiral solvents in asymmetric reactions [22]. Since that time, there have been many attempts to use chiral solvents in asymmetric reactions, but the enantioselectivities have been fairly low. This has led to the conclusion that asymmetric induction effected by chiral solvents. Even though the enantioselectivity observed for the electrochemical reduction of ketones in chiral amino ethers was low, it opened up the field to develop chiral solvents to influence the outcome of asymmetric reactions. Although a large number of chiral ionic liquids have been synthesized, only a limited number have been successful in affecting the outcome of asymmetric reactions.

Bao and co-workers have utilized CIILs as chiral solvents in the asymmetric Michael addition of diethyl malonate to 1,3-diphenyl-2-propenone (Scheme 18)
[23]. Better results were obtained in toluene than in DMSO or DMF as the co-solvent. Comparable chemical yields and enantioselectivities were obtained with CIIL bromide giving the best yield and ee of the three.

In 2003, Kiss et al. reported the palladium catalyzed Heck oxyarylation of 7-benzyloxy-2H-chromene with 2 -iodophenol using CIIL both as a chiral solvent and ligand (Scheme 21) [24]. The transformation gave low yields (13-28\%) and poor enantioselectivities (4-5\%) with $\mathrm{Pd}(\mathrm{OAc})_{2}$ and $\mathrm{PdCl}_{2}$ (Scheme 19).

\subsection{As Organocatalysts}

Metal-free catalysis of asymmetric reactions by simple organocatalysts has become an important area of research in recent years [25]. Pyrrolidine catalysts have been used successfully for the direct asymmetric aldol and Michael addition reactions [25], which are regarded as two of the most powerful carbon-carbonbond-forming reactions inorganic synthesis [25]. For these reactions, the organocatalyst is usually used in substantial quantity, and the efficient recovery and reuse of the organocatalyst are a major concern. Therefore, there is a need to develop new organocatalysts, which are easily recyclable and possess enhanced catalytic abilities. In this regard,
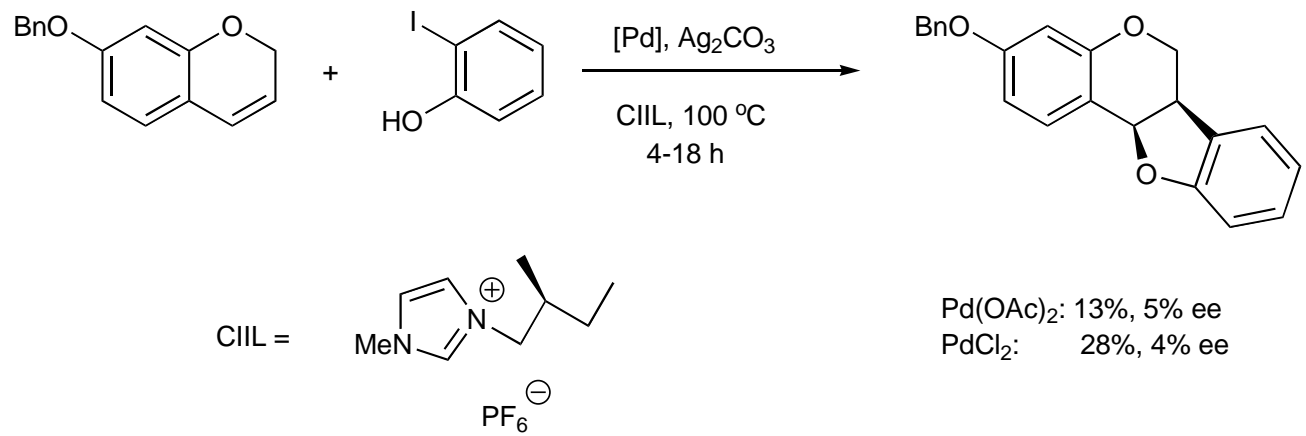

$\mathrm{Pd}(\mathrm{OAc})_{2}: 13 \%, 5 \%$ ee

$\mathrm{PdCl}_{2}: \quad 28 \%, 4 \%$ ee

Scheme 19: CIIL promoted asymmetric Heck oxyarylation reaction. 


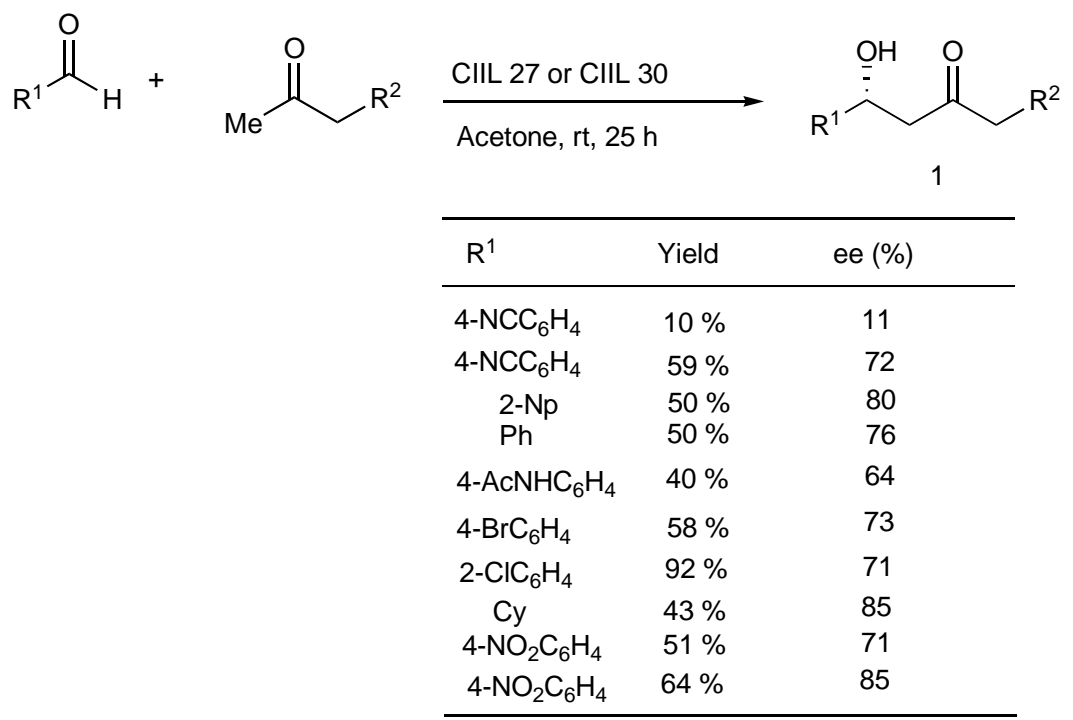

Scheme 20: CIIL promoted asymmetric aldol reaction.

ionic liquids that contain specific functionalities and are capable of acting as organocatalysts have received much attention recently. One advantage of ionic-liquidbased chiral organocatalysts is that they can be recovered easily from the reaction mixtures simply by capitalizing on their solubility characteristics.

Miao and Chan reported proline based CIIL 27 as organo catalyst for the direct asymmetric aldol reaction of 4-cyanobenzaldehyde with acetone, but obtained the aldol product, $\mathbf{1 a}$, in only $10 \%$ yield and $11 \%$ ee. CIIL $\mathbf{3 0}$ fared better as organocatalyst under the same conditions, leading to $1 \mathrm{a}$ in $59 \%$ yield and $72 \%$ see (Scheme 20) [19]. The results indicate that the acidic proton of proline is essential for efficient catalysis to occur. Thus, the aldol reaction of a broad range of aldehyde acceptors, including aromatic and aliphatic aldehydes, and two ketone donors, acetone and 2butanone, was carried out in good yields and enantioselectivities in the presence of organo catalyst 30 under the same conditions. Furthermore, the authors carried out the reactions of 4-nitrobenzaldehydein deuterated acetone with CIIL $\mathbf{3 0}$ or proline as catalyst, respectively, and proved that CIIL $\mathbf{3 0}$ is a more efficient organocatalyst than proline itself. The recyclability of CIIL $\mathbf{3 0}$ as organocatalyst was also examined (Scheme 21) [19]. CIIL 30 was recycled and reused at least four times in the same reaction without significant loss in yield and enantioselectivity.

Functionalized CIILs 32 and 33 have been employed as highly efficient asymmetric organocatalysts for the Michael addition of cyclohexanone to nitroalkenes (Scheme 22) [18]. CIILs 32a-c and 33a, lacking a substituent at C-2 of the imidazole ring, were superiorto their 2'-methyl counterparts (32a-c and 33b) in terms of yields and selectivity. Introduction of a protic group $(\mathrm{OH})$ in the side chain did not improve the catalytic activity and selectivity, and CIILs with $\mathrm{Br}^{-}$and $\mathrm{BF}^{-}$were much more active and selective than those with PF6 ${ }^{-}$.

Headly and his co-workers has developed a new type of pyrrolidine based CIIL which catalyzes the Michael addition of various aldehydes to nitrostryenes in $\mathrm{Et}_{2} \mathrm{O}$ at $4{ }^{\circ} \mathrm{C}$ with moderate yields $(\leq 64 \%)$, good

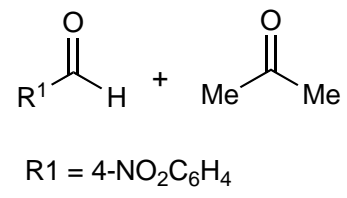

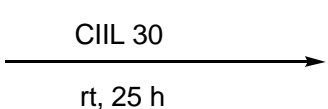

rt, $25 \mathrm{~h}$

\begin{tabular}{ccc} 
& & $1 \mathrm{a}$ \\
Cycle & Yield(\%) & ee(\%) \\
\hline 1 & 68 & 85 \\
2 & 68 & 85 \\
3 & 66 & 83 \\
4 & 64 & 82 \\
\hline
\end{tabular}

Scheme 21: Recyclability of CIIL 30. 
<smiles>CC([C@H](C)C(=O)[N+](=O)/C=C/c1ccccc1)C(F)(F)F</smiles><smiles></smiles>

CIIL 32a, $\mathrm{X}=\mathrm{Br}$ CIIL 32b, $X=\mathrm{BF}_{4}$ CIIL 32c, $X=P F_{6}$<smiles></smiles>

CIIL 33a, R= H

CIIL 33b, $R=M e$

\begin{tabular}{cccccc}
\hline Cycle & Cat & Time & Yield (\%) & Syn/ Anti & ee (\%) \\
\hline 1 & $40 \mathrm{a}$ & $20 \mathrm{~h}$ & 97 & $97: 3$ & 97 \\
1 & $40 \mathrm{~b}$ & $16 \mathrm{~h}$ & 100 & $96: 4$ & 94 \\
1 & $40 \mathrm{c}$ & $12 \mathrm{~h}$ & 40 & $96: 4$ & 82 \\
1 & $41 \mathrm{a}$ & $18 \mathrm{~h}$ & 86 & $97: 3$ & 89 \\
1 & $41 \mathrm{~b}$ & $18 \mathrm{~h}$ & 25 & $94: 6$ & 70 \\
\hline
\end{tabular}

Scheme 22: CIIL catalyzed Michael addition of cyclohexanone to nitroalkenes.

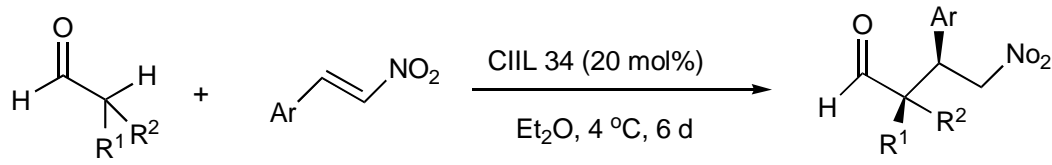

\begin{tabular}{lllccc}
\hline $\mathrm{R}^{1}$ & $\mathrm{R}^{2}$ & $\mathrm{Ar}$ & Yield (\%) & Syn/ Anti & ee (\%) \\
\hline $\mathrm{Me}$ & $\mathrm{Me}$ & $\mathrm{Ph}$ & 58 & $\ldots$. & 82 \\
$n-\mathrm{Bu}$ & $\mathrm{H}$ & $\mathrm{Ph}$ & 64 & $97: 03$ & 68 \\
$n-\mathrm{Bu}$ & $\mathrm{H}$ & $p-\mathrm{Tol}$ & 60 & $96: 04$ & 67 \\
$n-\mathrm{Pr}$ & $\mathrm{H}$ & $p-\mathrm{An}$ & 29 & $92: 08$ & 67 \\
$i-\mathrm{Pr}$ & $\mathrm{H}$ & $\mathrm{Ph}$ & 53 & $96: 04$ & 66 \\
$i-\mathrm{Pr}$ & $\mathrm{H}$ & $p-\mathrm{Tol}$ & 64 & $97: 03$ & 73 \\
$n-\mathrm{Pr}$ & $\mathrm{H}$ & $\mathrm{Ph}$ & 49 & $89: 11$ & 64 \\
$n-\mathrm{Pr}$ & $\mathrm{H}$ & $p-\mathrm{Tol}$ & 38 & $96: 04$ & 68 \\
$\mathrm{a}, \mathrm{b}$ & $\mathrm{a}, \mathrm{b}$ & $\mathrm{Ph}$ & 38 & $95: 05$ & 88 \\
\hline
\end{tabular}

Scheme 23: CIIL catalized asymmetric Michael addition of various aldehydes to nitrostryenes.

enantioselectivities $(\leq 82 \% \quad$ ee $), \quad$ and high diastereoselectivities (syn:anti $\leq$ 97:3) (Scheme 23) [21]. Moreover, catalyst also catalyzes the Michael addition of cyclohexanoneto trans- $\beta$-nitrostyrene in acetonitrile at room temperature to give the adduct in moderate yield and high stereoselectivities (syn:anti = $95: 5,88 \%$ ee). Our results also demonstrate that the presence of acidic hydrogen is necessary for the selectivity; the acidic $\mathrm{N}-\mathrm{H}$ adjacent to the electronwithdrawing sulfonyl group plays an important role in the selectivity of the reaction. The catalyst is easily recycled without loss of activity.

\subsection{Asymmetric Aldol Reaction}

Lombardo et al. described the synthesis of "iontagged L-prolines" as organo catalysts for asymmetric aldol reactions [26-28]. These are essentially L-prolinebased CIILs (Scheme 24). They observed a higher efficiency with the lipophilic bis(trifluoromethylsulfonyl) imide $\left(\mathrm{NTf}_{2}{ }^{-}\right)$counter anion as compared with the $\mathrm{BF}_{4}$ anion. This was further improved by theuse of aqueous biphasic conditions instead of using the neationic liquid ([bmim] $\left.\left[\mathrm{NTf}_{2}\right]\right)$ as the solvent [27]. The final improvement of this L-proline-based catalyst was achieved by using the cis-geometry of the imidazolium ionic moiety toproline as opposed to the transgeometry present in their previous publications. As shown by the example in Scheme 24, the yield improved from $37 \%$ to $87 \%$ by the use of cis-CIIL compared with the trans-CIIL. No organic solvent was used for the reaction. However, 1.2 equivalents of water and 5molar excess of liquid ketone as the aldol 


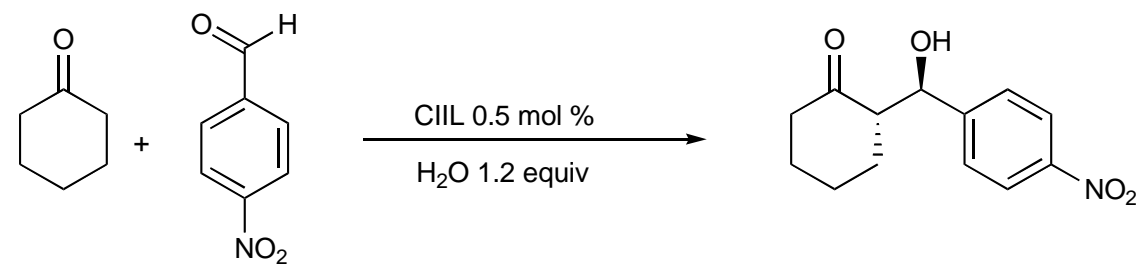

\begin{tabular}{ccccc}
\hline CIIL & Condition & Yield (\%) & ee (\%) & Syn/ Anti \\
\hline & $5 \mathrm{~h}$ at $20{ }^{\circ} \mathrm{C}$ & 37 & 99 \\
\hline
\end{tabular}

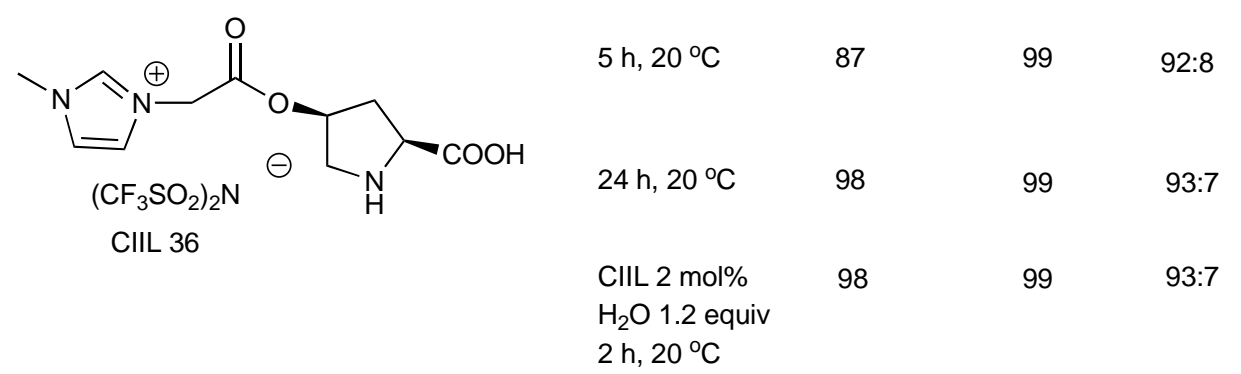

Scheme 24: Assymetric aldol reaction catalyzed by L-proline modified CIILs.

donor were used to ensure homogeneous conditions. Exceptionally, high turnover numbers for most reactive aromatic aldehydes were observed (TON $=196$ for the cis-CIIL, $0.5 \mathrm{~mol} \%$, and $24 \mathrm{~h}$ reaction time). Also, high yields (up to $99 \%$ ), excellent enantioselectivities (>99\% ee), and diastereo- selectivities (anti:syn up to 95:5) were obtained with this organocatalyst.

In 2008, Zlotin and coworkers synthesized the amphiphilic chiral imidazolium salts derived from (S)proline and accompanying anions $\mathrm{BF}_{4}{ }^{-}$and $\mathrm{PF}_{6}^{-}$ (Scheme 25). These are structurally similar to the previously described class but have longer alkane chains on the imidazolium moiety for added hydrophobicity. Organocatalysis by these CIILs between cycloketones and aromatic aldehydes proved to be efficient (up to $95 \%$ yield), stereoselective (up to $>99 \%$ ee) and diastereoselective (anti:syn up to $97: 3$ ). Good recover ability for up to 5 cycles was also observed. Following this success, in 2009, they synthesized a series of CIILs with different hydroxyl- $\alpha$ amino acids such as proline, serine, and threonine and different cationic charge carrying moieties such as imidazolium and pyridinium (Scheme 26) [29]. The incorporation of the $\mathrm{NTf}_{2}{ }^{-}$anion and pyridinium or 4-(5nolyl)-pyridinium cations instead of imidazolium-based cations were intended to improve the hydrophobicity of the CIIL. These new CIILs are amphiphilic and their catalytic properties in the "on water" aldol reaction has been examined. It is interesting to note that the CIIL 39 with a pyridinium cation and $\mathrm{PFF}_{6}^{-}$anion did not catalyze the aldol reaction under the conditions examined, whereas the CIIL 40 with4-(5-nolyl)pyridinum cation and same anion displayed high activity ( $97 \%$ yield) and enantioselectivity $(99 \%$ ee). This was correlated to the hydrophobicity of the ionic liquids. Despite the presence of $\mathrm{PF}_{6}{ }^{-}$anion, CIIL 39 was water soluble, whereas CIIL 40 was insoluble in water. This enabled the organocatalyst to reside at the water/organic solvent interface facilitating the reaction. The authors also stated that CIIL 40 retained its catalytic activity and selectivity after eight reaction cycles. In their most recent publication on this topic, Zlotin and coworkers further modified these organocatalysts by removing the free carboxylic acid group on the proline structure by converting it to an amide [30]. This modification optimized the catalyst's hydrophobic/hydrophilic properties to obtain maximum catalytic efficiency in an aqueous environment compared with the catalysts with free carboxylic groups (Scheme 27). They obtained almost quantitative yields and good enantioselectivities (up to $99 \%$ ee with CIIL 


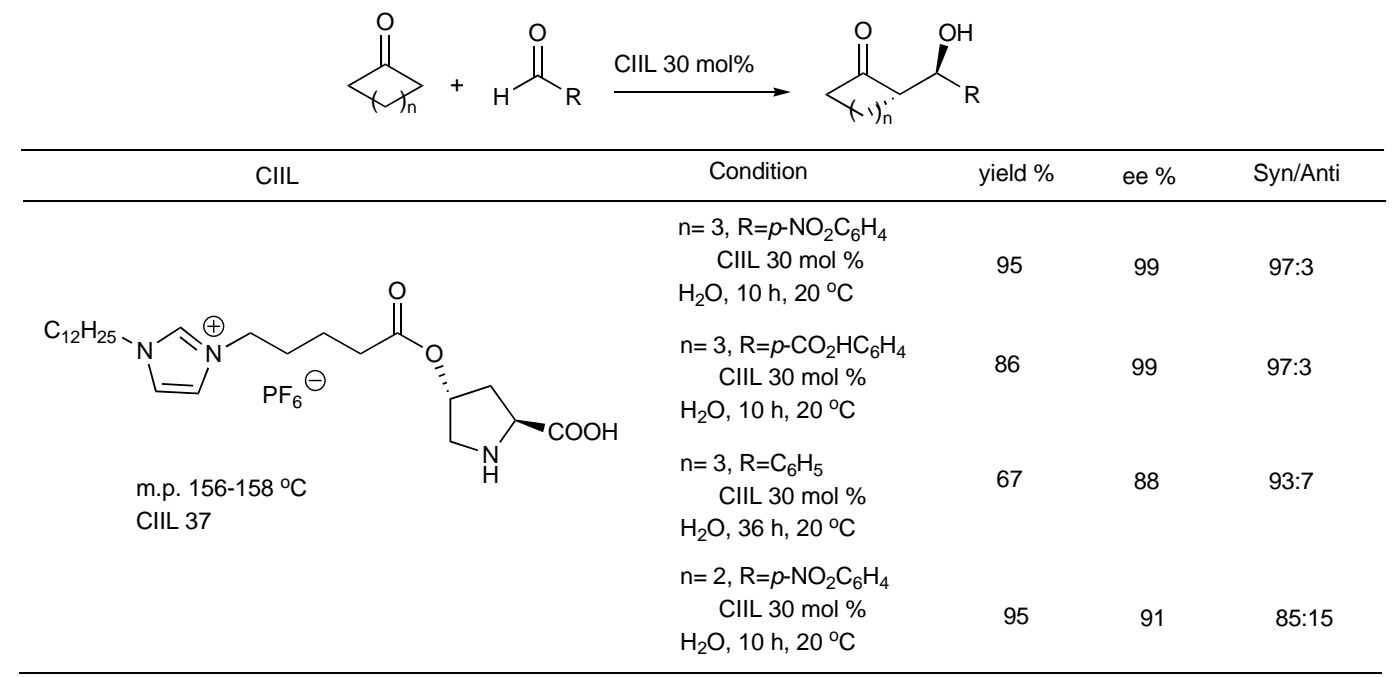

Scheme 25: CIIL promoted asymmetric aldol reation.

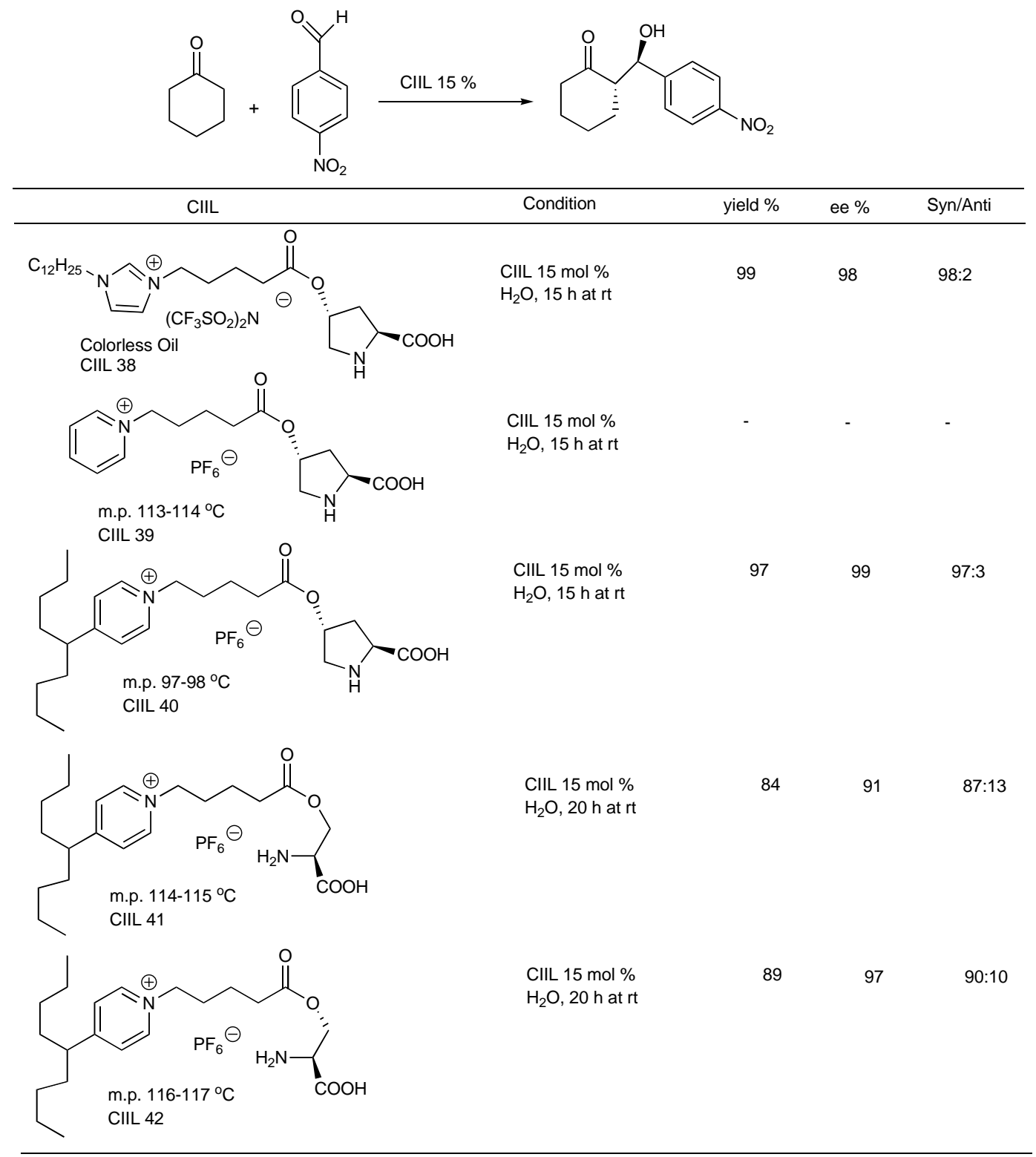

Scheme 26: Imidazolium and pyridinium based CIL promoted asymmetric aldol reaction. 


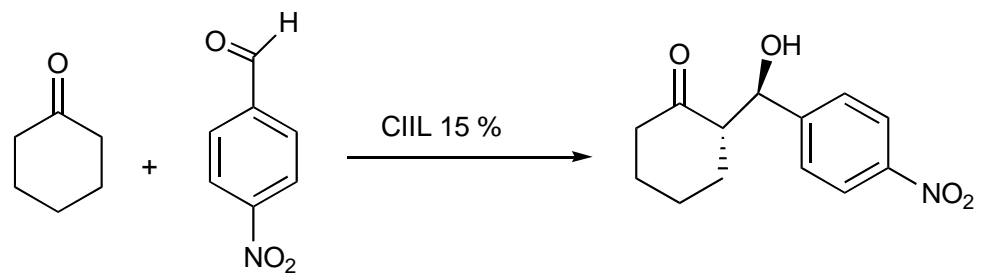

(10) yield \%

Scheme 27: CIIL catalyzed asymmetric aldol reaction.

58) and diastereoselectivities (anti:syn up to 99:1 with CIIL 43 at $3^{\circ} \mathrm{C}$ for $15 \mathrm{~h}$ ) in the presence of large excess of water. Selectivity was notably higher for the more hydrophobic catalyst 43 as compared with 44 . Finally, it was noted that CILs containing imidazole moiety exhibited promising catalytic activity that the others.

\subsection{Asymmetric Diels-Alder Reaction}

Howarth et al. used dialkylimidazoliumsalts (chiral and achiral) as Lewis-acids to catalyze the reaction between crotonaldehyde or methacrolein with cyclopentadiene. The chirality of the ionic liquid did no tseem to have much influence on the stereochemistry as the enantiomeric excess was less than $5 \%$, whereas the endo:exo product ratios were almost the same for both chiral and achiral ILs [31]. Since then ionic liquids have been tried both as acid catalysts and as the solvent in asymmetric Diels-Alder reaction to improve the stereoselectivity.

In 2006, Pernak and coworkers used protic imidazolium ionic liquids as the reaction media for cyclopentadiene and two dienophiles (dimethyl maleate and methyl acrylate) that resulted in good endo/exo selectivities (up to 3.9:1; Scheme 28) [32]. The racemic DL-lactate ionic liquid $\mathbf{4 5}$ chiral L-lactate ionic liquid $\mathbf{4 6}$ and both performed almost identically.

Vo-Thanh and coworkers designed different CIILs to be used as the reaction media in an aza-Diels-Alder reaction between Danishefsky's diene and chiral imine (Scheme 29). The reactions involved only the diene, chiral imines, and the CIIL, 47 and 48, whereas no other acid catalyst or organic solvent was used [33].

The first enantioselective Diels-Alder reaction with a CIIL was reported by Doherty et al. [34]. They used imidazolium modified bis-oxazoline CIIL 49 (Scheme 30) as a chiral ligand in the copper(II)-catalyzed reaction of $\mathrm{N}$-acryloyl and $\mathrm{N}$-crotonoyloxazolidinones with cyclopentadiene and 1,3-cyclohexadiene. Higher rates were achieved in reactions carried out in anionic liquid [emim] $\left[\mathrm{NTf}_{2}\right]$ compared with dichloromethane. Higher yields (up to 100\%) and enantioselectivities (95\% ee) were also achieved with the IL. The catalyst could be recycled 10 times without loss of activity.

In 2010, Wang and coworkers reported the successful application of 2-pyrrolidinecarboxylicacid 


in

Scheme 28: Asymmetric Diels-Alder reaction catalyzed by CIILs.

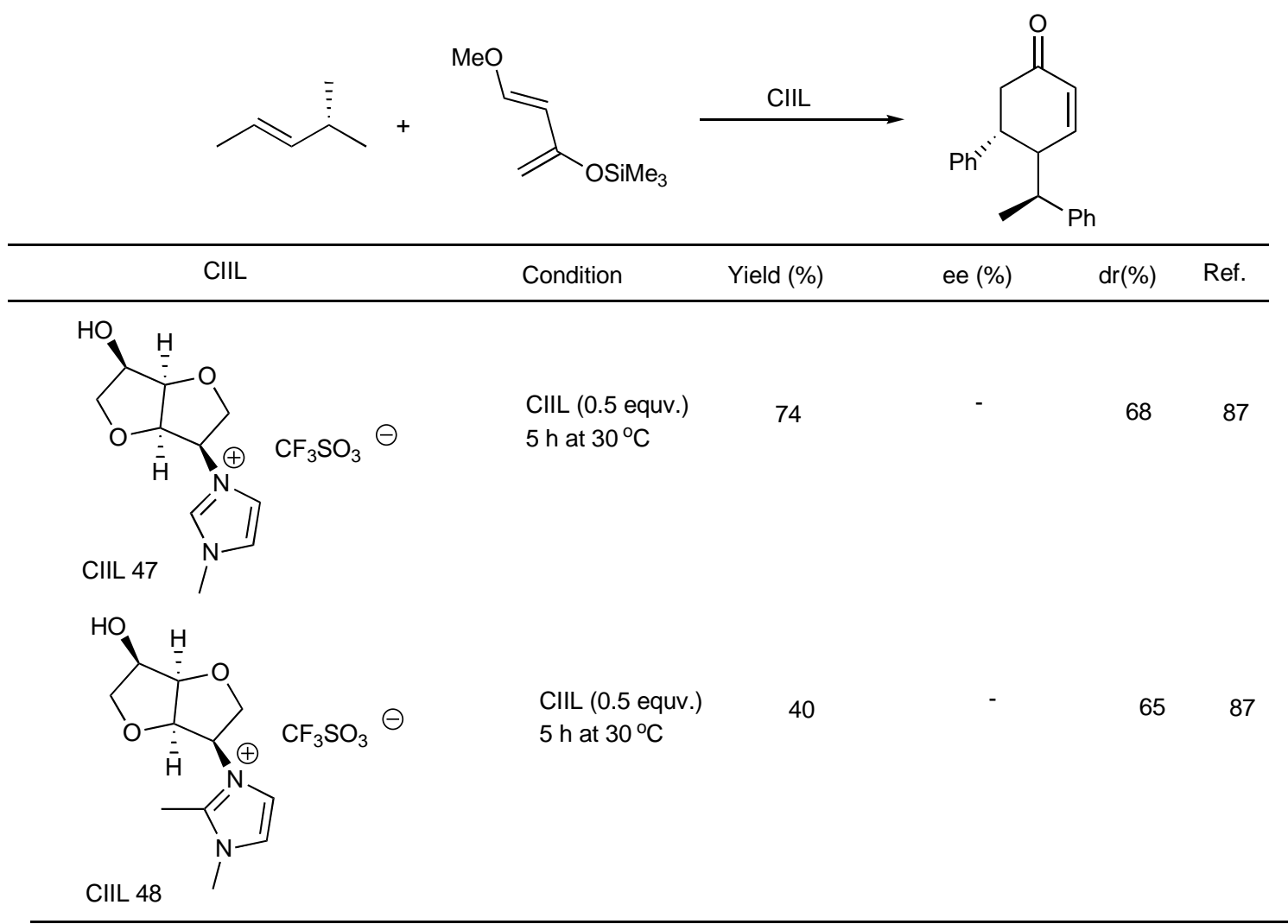

Scheme 29: Aza-Diels-Alder reaction catalyzed by CIILs.

derived CIIL 50 as a catalyst for the aza-Diels-Alder reaction (Scheme 31) [35]. The products were obtained in good yields (up to 93\%) with excellent enantioselectivities (>99\% ee) and diastereoselectivities (endo:exo up to >99:1). The catalytic system could be recycled six times without loss of activity.

\subsection{Enantioselective Hydrogenation}

Transition metal catalysts consisting of chiral metal complexes are commonly used in enantioselective hydrogenation reactions. Schulz et al. reported the first asymmetric synthesis where this reaction was carried out solely via the ion-pairing effect of a CIL as the only source of chirality [36]. The chiral anionic ionic liquid $\mathrm{N}$ - 


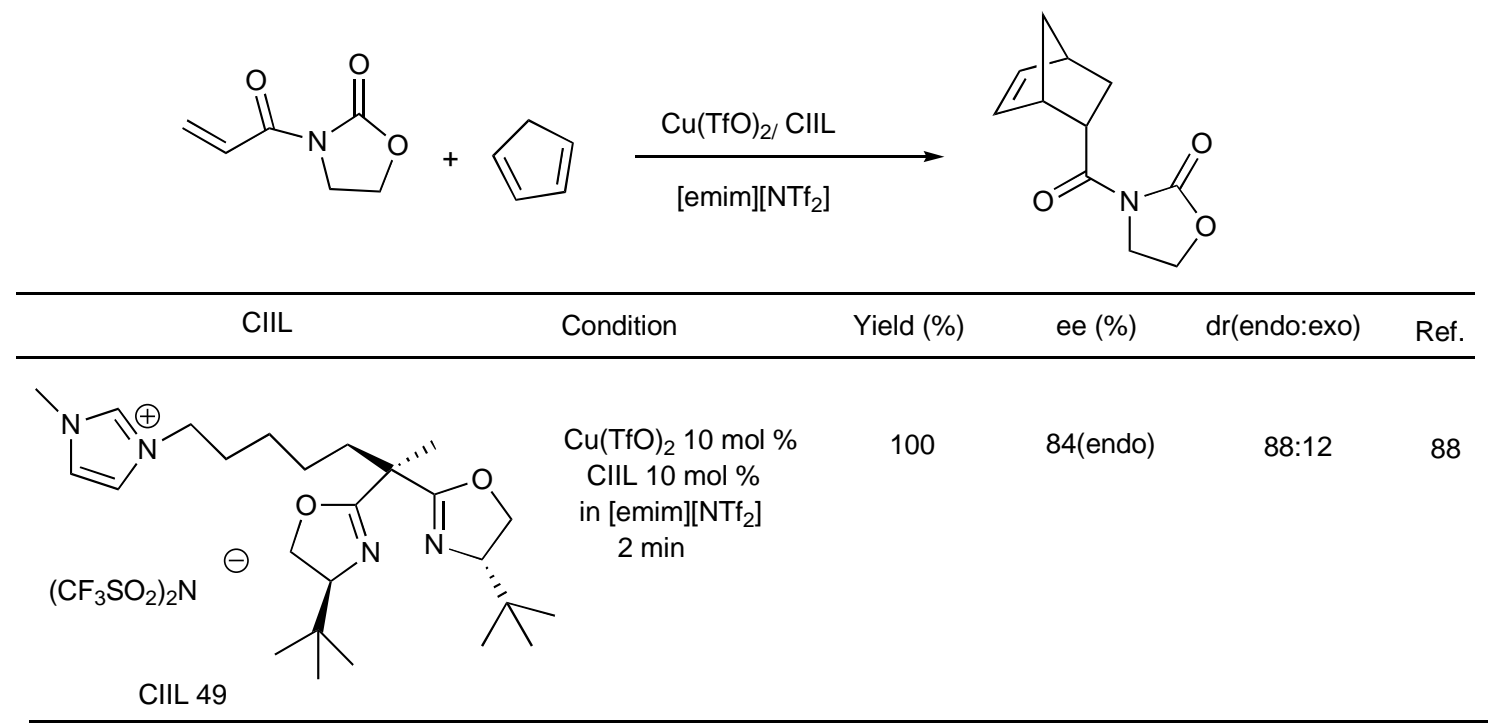

Scheme 30: Bis-oxazoline modified CIILs catalyzed aza-Diels-Alder reaction.

methylimidazolium $(R)$-camphorsulfonate (Scheme 32) was reacted with methyl vinyl ketone in a Michael-type addition to obtain $\mathrm{N}-(3$-oxobutyl)-N-methylimidazolium (R)-camphorsulfonate. The hydrogenation of this pro-chiral cation under heterogeneous conditions with $\mathrm{Ru} / \mathrm{C}$ catalyst in ethanol solution yielded the corresponding hydroxybutyl derivative in quantitative yield and up to $80 \%$ ee. The importance of the ionparing effect on enantioselectivity was confirmed by the strong dependence of concentration of the imidazolium salt to the observed enantiomeric excess of the hydrogenated cation as well as the absence of enantioselctivity $(<5 \%$ ee) for the hydrogenated product of the nonionic substrate acetophenone.

\subsection{Enantioselective Aldol Reaction}

Natalia and his group have reported a CIIL for asymmetric syn-aldol reactions using (S)Threonine/a, $\alpha-(S)$-diphenylvalinol, imidazolium chiral ionic liquid as a efficient catalyst [37]. Chiral ionic liquids containing (S)- or (R)-threonine amide and $\alpha, \alpha$ (S)-diphenylvalinol units have synthesized in the presence of the (S)-threonine-derived catalyst reactions between ketones with secondary carbon atom(s) at the $\alpha$-position with respect to the carbonyl group and aromatic (heteroaromatic) aldehydes afforded the corresponding syn-aldols in high yields (up to $99 \%$ ) and with high diastereo-(syn/anti up to $97: 3$ )

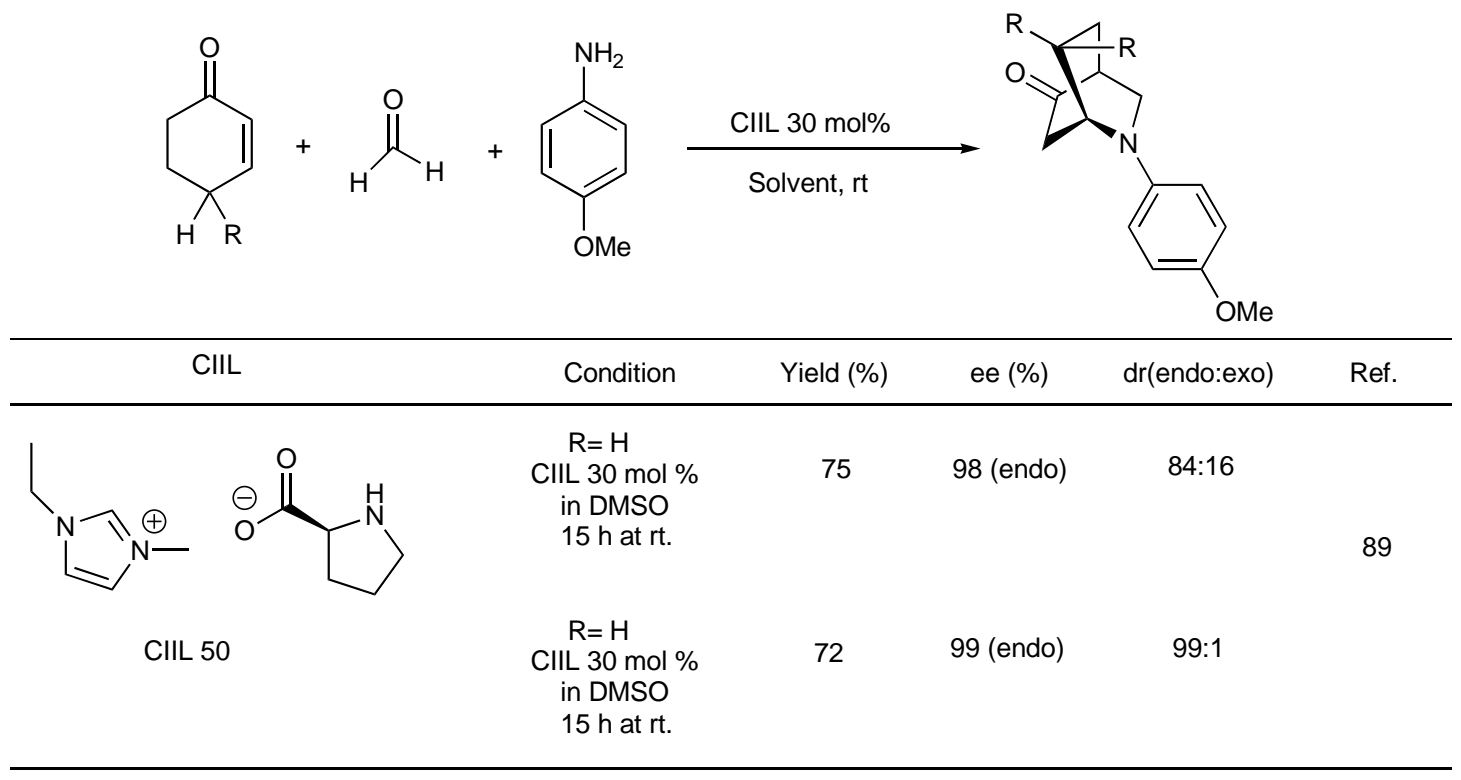

Scheme 31: 2-pyrrolidinecarboxylicacid derived CIIL as a catalyst for the aza-Diels-Alder reaction. 


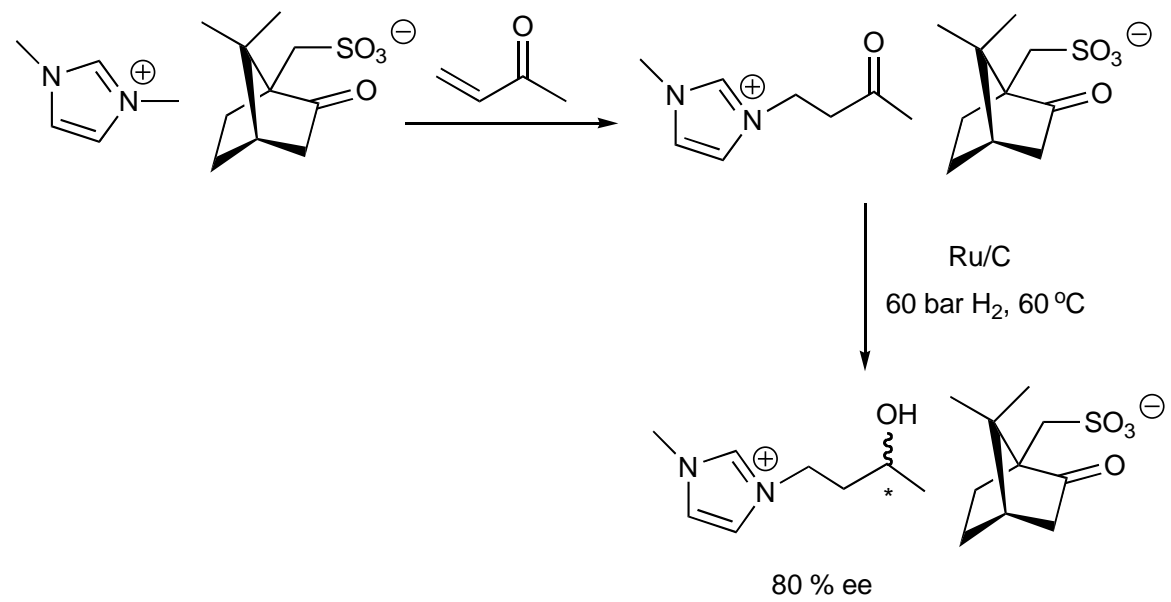

Scheme 32: Enantioselective hydrogenation of keto functionalized ionic liquid.

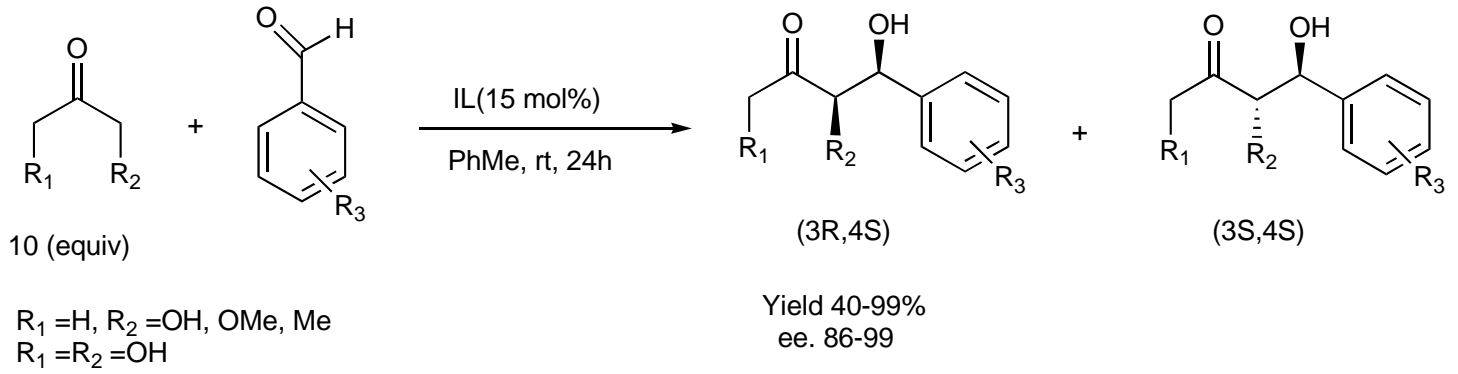

$\mathrm{IL}=$

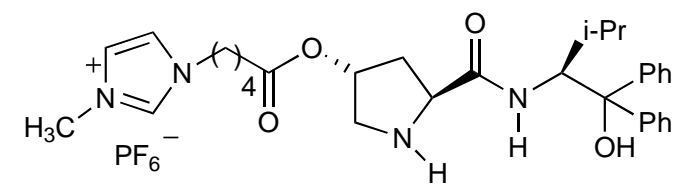

(S)-Threonine/ $\alpha, \alpha-(\mathrm{S})$-diphenylvalinol

Scheme 33: Aldol reaction in (S)-Threonine/a,a-(S)-diphenylvalinol chiral ionic liquid.

and enantioselectivity (up to $99 \%$ ee), which have maintained over three reaction cycles (Scheme 33).

\section{CONCLUSIONS}

The field of task-specific imidazolium based chiral ionic liquids is only in its infancy, but has a very promising future. The main advantage of these types of ionic liquids is that they are easily recovered and recycled without loss of activity when used for asymmetric reactions. Owing to a readily available source of chiral compounds such as naturally occurring amino acids and other compounds, which can serve as precursors in the synthesis of chiral ionic liquids-a new opportunity now exists for the synthesis of a very important class of organic compounds. The past few years have seen a tremendous growth in the number of chiral ionic liquids synthesized, but their effect on the outcome of asymmetric reactions has been limited, with most still giving low enantioselectivities. Therefore, a need exists for the development of additional, improved, and task-specific imidazolium chiral ionic liquids that are better able to influence the outcome of asymmetric reactions.

\section{ACKNOWLEDGEMENT}

We are thankful to UGC, New Delhi for providing the UGC-BSR Research Start-Up-Grant for Newly Recruited faculty [F. No. 20-1/2012(BSR)/208(3)/2012(BSR)].

\section{REFERENCES}

[1] Rogers RD, Seddon KR. Ionic Liquids; Industrial applications to Green Chemistry. ACS symposium series 2002; 488.

[2] Freemantle M. Designer Solvents. Chem Eng News 1998; 76: 32-7. http://dx.doi.org/10.1021/cen-v076n013.p032

[3] Walden P. Molecular weights and electrical conductivity of several fused salts. Bull Acad Imper Sci (St. Petersburg) 1914; 8: 405-22. 
[4] (a) Parvulescu VI, Hardacre C. Catalysis in ionic liquids. Chem Rev 2007; 107: 2615-65.

http://dx.doi.org/10.1021/cr050948h

(b) Rantwijk F, Sheldon RA. Biocatalysis in ionic liquids. Chem Rev 2007; 107: 2757-85.

http://dx.doi.org/10.1021/cr050946x

(c) Welton T. Room-temperature ionic liquids. solvents for synthesis and catalysis. Chem Rev 1999; 99: 2071-84.

http://dx.doi.org/10.1021/cr980032t

[5] (a) Pegot B, Vo-Thanh G, Gori D, Loupy A. First application of chiral ionic liquids in asymmetric Baylis-Hillman reaction. Tetrahedron Lett 2004; 45: 6425-8.

http://dx.doi.org/10.1016/j.tetlet.2004.06.134

(b) Ding J, Desikan V, Han X, et al. Use of Chiral Ionic Liquids as solvents for the enantioselective photoisomerization of dibenzobicyclo[2.2.2]octatrienes. Org Lett 2005; 7: 335.

http://dx.doi.org/10.1021/01047599i

(c) Wang Z, Wang Q, Zhang Y, Bao W. Synthesis of new chiral ionic liquids from natural acids and their applications in enantioselective Michael addition. Tetrahedron Lett 2005; 46: 4657-60.

http://dx.doi.org/10.1016/..tetlet.2005.04.134

(d) Luo S, Mi X, Zhang L, Liu S, Xu H, Cheng JP. Functionalized chiral ionic liquids as highly efficient asymmetric organocatalysts for michael addition to nitroolefins. Angew Chem Int Ed 2006; 45: 3093-7.

http://dx.doi.org/10.1002/anie.200600048

(e) Gausepohl R, Buskens P, Kleinen J, et al. Highly enantioselective Aza-Baylis-Hillman reaction in a chiral reaction medium. Angew Chem Int Ed 2006; 45: 3689-92. http://dx.doi.org/10.1002/anie.200600327

(f) Branco LC, Gois PMP, Lourenço NMT, Kurteva VB, Afonso CAM. Simple transformation of crystalline chiral natural anions to liquid medium and their use to induce chirality. Chem Commun 2006; 2371-2.

http://dx.doi.org/10.1039/b600816j

(g) Malhotra SV, Wang Y. Application of chiral ionic liquids in the copper catalyzed enantioselective 1,4-addition of diethylzinc to enones. Tetrahedron: Asymmetry 2006; 17: $1032-5$.

http://dx.doi.org/10.1016/j.tetasy.2006.03.030

(h) Padar P, Bokros A, Paragi G, et al. Single diastereomers of polyhydroxylated 9-Oxa-1-azabicyclo[4.2.1]nonanes from intramolecular 1,3-dipolar cycloaddition of $\omega$-unsaturated nitrones. J Org Chem 2006; 71: 8669-72. http://dx.doi.org/10.1021/jo061503b

(i) Pegot B, Nguyen VBO, Gori D, Vo-Thanh G. Asymmetric aza-Diels-Alder reaction of Danishefsky's diene with imines in a chiral reaction medium. Beilstein $\mathrm{J}$ Org Chem 2006; 2: 18.

http://dx.doi.org/10.1186/1860-5397-2-18

(j) Ni B, Zhang Q, Headley AD. Functionalized chiral ionic liquid as recyclable organocatalyst for asymmetric Michael addition to nitrostyrenes. Green Chem 2007; 9: 737-9.

http://dx.doi.org/10.1039/b702081c

(I) Nguyen VBO, Vo-Thanh G. Synthesis of novel chiral ammonium-based ionic liquids derived from isosorbide and their applications in an asymmetric Aza Diels-Alder reaction. Lett Org Chem 2007; 4: 158-67. http://dx.doi.org/10.2174/157017807780737219

(m) Yadav LDS, Rai A, Rai V, Awasthi C. Chiral ionic liquidcatalyzed Biginelli reaction: stereoselective synthesis of polyfunctionalized perhydropyrimidines. Tetrahedron 2008; 64: $1420-90$ http://dx.doi.org/10.1016/j.tet.2007.11.044

(n) Baudequin C, Bregeon DJ, Levillain J, Guillen F, Plaquevent JC, Gaumont AC. Chiral ionic liquids, a renewal for the chemistry of chiral solvents? Design, synthesis and applications for chiral recognition and asymmetric synthesis. Tetrahedron: Asymmetry 2005; 16: 3921-45.

http://dx.doi.org/10.1016/..tetasy.2005.10.026

(o) Ding J, Armstrong DW. Chiral ionic liquids: synthesis and applications. Chirality 2005; 17: 281-92.

http://dx.doi.org/10.1002/chir.20153

(p) Chen X, Li X, Hu A, Wang F. Advances in chiral ionic liquids derived from natural amino acids. Tetrahedron: Asymmetry 2008; 19: 1-14.

http://dx.doi.org/10.1016/j.tetasy.2007.11.009

(q) Wang Z, Wang Q, Zhang Y, Bao W. Synthesis of new chiral ionic liquids from natural acids and their applications in enantioselective Michael addition. Tetrahedron Lett 2005; 46: 4657-660.

http://dx.doi.org/10.1016/j.tetlet.2005.04.134

(r) Schulz PS, Muller N, Bosmann A, Wasserscheid P. Effective chirality transfer in ionic liquids through ion-pairing effects. Angew Chem Int Ed 2007; 46: 1293-5. http://dx.doi.org/10.1002/anie.200604406

[6] Earle MJ, McCormac PB, Seddon KR. Diels-Alder reactions in ionic liquids. A safe recyclable alternative to lithium perchlorate-diethyl ether mixtures. Green Chem 1999; 1: 235.

http://dx.doi.org/10.1039/a808052

[7] Fukumoto K, Yoshizawa M, Ohno H. Room temperature ionic liquids from 20 natural amino acids. J Am Chem Soc 2005; 127: 2398-9.

http://dx.doi.org/10.1021/ia043451i

[8] Fukumoto K, Ohno H. Design and synthesis of hydrophobic and chiral anions from amino acids as precursor for functional ionic liquids. Chem Commun 2006; 3081-3. http://dx.doi.org/10.1039/b606613e

[9] Ding J, Desikan V, Han X, et al. Use of chiral ionic liquids as solvents for the enantioselective photoisomerization of dibenzobicyclo[2.2.2]octatrienes. Org Lett 2005; 7: 335-7. http://dx.doi.org/10.1021/ol047599i

[10] Bao W, Wang Z, Li Y. Synthesis of chiral ionic liquids from natural amino acids. J Org Chem 2003; 68: 591-3. http://dx.doi.org/10.1021/j0020503i

[11] Genisson $Y$, Lauth-de Viguerie N, Andre C, Baltas M, Gorrichon L. New chiral imidazolinic derivatives. Tetrahedron: Asymmetry 2005; 16: 1017-23. http://dx.doi.org/10.1016/j.tetasy.2005.01.014

[12] Kim EJ, Ko SY, Dziadulewicz EK. Mitsunobu alkylation of imidazole: a convenient route to chiral ionic liquids. Tetrahedron Lett 2005; 46: 631-3. http://dx.doi.org/10.1016/..tetlet.2004.11.144

[13] Machado MY, Dorta R. Synthesis and characterization of chiral imidazolium salts. Synthesis 2005; 2473-5.

[14] Tosoni M, Laschat S, Baro A. Synthesis of novel chiral ionic liquids and their phase behavior in mixtures with smectic and nematic liquid crystals. Helv Chim Acta 2004; 87: 2742-9. http://dx.doi.org/10.1002/hlca.200490247

[15] Luo SP, Xu DQ, Yue HD, Wang LP, Yang WL, Xu ZY Synthesis and properties of novel chiral-amine-functionalized ionic liquids. Tetrahedron: Asymmetry 2006; 17: 2028-33. http://dx.doi.org/10.1016/j.tetasy.2006.07.018

[16] Ni B, Headley AD, Li G. Design and synthesis of C-2 substituted chiral imidazolium ionic liquids from amino acid derivatives. J Org Chem 2005; 70: 10600-2. http://dx.doi.org/10.1021/j0051888

[17] Ou WH, Huang ZZ. Retracted article: An efficient and practical synthesis of chiral imidazolium ionic liquids and their application in an enantioselective Michael reaction. Green Chem 2006; 8: 731-4. http://dx.doi.org/10.1039/b604801c

[18] Luo S, Mi X, Zhang L, Liu S, Xu H, Cheng JP. Functionalized chiral ionic liquids as highly efficient asymmetric 
organocatalysts for Michael addition to nitroolefins. Angew Chem Int Ed 2006; 45: 3093-7.

http://dx.doi.org/10.1002/anie.200600048

[19] Miao W, Chan TH. Ionic-liquid-supported organocatalyst: efficient and recyclable ionic-liquid-anchored proline for asymmetric Aldol reaction. Adv Synth Catal 2006; 348: 17118.

http://dx.doi.org/10.1002/adsc.200606059

[20] Guillen F, Brégeon D, Plaquevent J-C. (S)-Histidine: the ideal precursor for a novel family of chiral aminoacid and peptidic ionic liquids. Tetrahedron Lett 2006; 47: 1245-8. http://dx.doi.org/10.1016/j.tetlet.2005.12.090

[21] Ni B, Zhang Q, Headley AD. Functionalized chiral ionic liquid as recyclable organocatalyst for asymmetric Michael addition to nitrostyrenes. Green Chem 2007; 9: 737-9. http://dx.doi.org/10.1039/b702081c

[22] Seebach D, Oei HA. Mechanism of electrochemical pinacolization. the first asymmetric synthesis in a chiral medium. Angew Chem Int Ed Engl 1975; 14: 634-6. http://dx.doi.org/10.1002/anie.197506342

[23] Wang Z, Wang Q, Zhang Y, Bao W. Synthesis of new chiral ionic liquids from natural acids and their applications in enantioselective Michael addition. Tetrahedron Lett 2005; 46: 4657-60.

http://dx.doi.org/10.1016/i.tetlet.2005.04.134

[24] Kiss L, Kurtan T, Antus S, Brunner H. Further insight into the mechanism of Heck oxyarylation in the presence of chiral ligands. Arkivoc 2003; 5: 69-76.

[25] (a) Jarvo ER, Miller SJ. Amino acids and peptides as asymmetric organocatalysts. Tetrahedron 2002; 58: 2481-95. http://dx.doi.org/10.1016/S0040-4020(02)00122-9

(b) List B. Proline-catalyzed asymmetric reactions. Tetrahedron 2002; 58: 5573-90. http://dx.doi.org/10.1016/S0040-4020(02)00516-1

(c) List B. Enamine catalysis is a powerful strategy for the catalytic generation and use of carbanion equivalents. Acc Chem Res 2004; 37: 548-57.

http://dx.doi.org/10.1021/ar0300571

(d) Dalko PI, Moisan L. In the golden age of organocatalysis. Angew Chem Int Ed 2004; 43: 5138-75. http://dx.doi.org/10.1002/anie.200400650

(e) Notz W, Tanaka F, Barbas CF. Enamine-based organocatalysis with proline and diamines: the development of direct catalytic asymmetric Aldol, Mannich, Michael, and Diels-Alder reactions. Acc Chem Res 2004; 37: 580-91. http://dx.doi.org/10.1021/ar0300468

(f) Lelais G, MacMillan DWC. Asymmetric synthesis enabled by metal-free catalysis. Aldrichimica Acta 2006; 39: 79-87.

[26] Lombardo M, Pasi F, Easwar S, Trombini C. An improved protocol for the direct asymmetric Aldol reaction in ionic liquids, catalysed by onium ion-tagged prolines. Adv Synth Catal 2007; 349: 2061-5.

http://dx.doi.org/10.1002/adsc.200700136
[27]

Lombardo M, Pasi F, Easwar S, Trombini C. Direct asymmetric Aldol reaction catalyzed by an imidazoliumtagged trans-4-hydroxy-L-proline under aqueous biphasic conditions. Synlett 2008; 2471-4.

http://dx.doi.org/10.1055/s-2008-1078055

[28] Lombardo M, Pasi F, Easwar S, Trombini C. The ion tag strategy as a route to highly efficient organocatalysts for the direct asymmetric Aldol reaction. Adv Synth Catal 2009; 351 : 276-82.

http://dx.doi.org/10.1002/adsc.200800608

[29] Siyutkin DE, Kucherenko AS, Struchkova MI, Zlotin SG. A novel (S)-proline-modified task-specific chiral ionic liquid-an amphiphilic recoverable catalyst for direct asymmetric aldol reactions in water. Tetrahedron Lett 2008; 49: 1212-6. http://dx.doi.org/10.1016/j.tetlet.2007.12.044

[30] Siyutkin DE, Kucherenko AS, Zlotin SG. Hydroxy-a-amino acids modified by ionic liquid moieties: recoverable organocatalysts for asymmetric aldol reactions in the presence of water. Tetrahedron 2009; 65: 1366-72. http://dx.doi.org/10.1016/j.tet.2008.12.045

[31] Howarth J, Hanlon K, Fayne D, McCormac P. moisture stable dialkylimidazolium salts as heterogeneous and homogeneous lewis acids in the diels-alder reaction. Tetrahedron Lett 1997; 38: 3097-100. http://dx.doi.org/10.1016/S0040-4039(97)00554-6

[32] Janus E, Goc-Maciejewska I, Lozynski M, Pernak J. DielsAlder reaction in protic ionic liquids. Tetrahedron Lett 2006; 47: 4079-83.

http://dx.doi.org/10.1016/i.tetlet.2006.03.172

[33] Van BN, Aupoix A, Vo-Thanh G. Synthesis of novel chiral imidazolium-based ionic liquids derived from isosorbide and their applications in asymmetric aza Diels-Alder reaction. Tetrahedron 2009; 65: 2260-5. http://dx.doi.org/10.1016/j.tet.2009.01.055

[34] Doherty S, Goodrich P, Hardacre C, et al. Recyclable copper catalysts based on imidazolium-tagged bis(oxazolines): a marked enhancement in rate and enantioselectivity for DielsAlder reactions in ionic liquid. Adv Synth Catal 2007; 349: 951-63.

http://dx.doi.org/10.1002/adsc.200600531

[35] Zheng X, Qian Y, Wang Y. Direct asymmetric aza DielsAlder reaction catalyzed by chiral 2-pyrrolidinecarboxylic acid ionic liquid. Catal Commun 2010; 11: 567-70. http://dx.doi.org/10.1016/j.catcom.2009.12.021

[36] Schulz PS, Mueller N, Boesmann A, Wasserscheid P. Effective chirality transfer in ionic liquids through ion-pairing effects. Angew Chem IntEd Engl 2007; 46: 1293-5. http://dx.doi.org/10.1002/anie.200604406

[37] Natalia AL, Alexandr SK, Dmitry ES, Sergei GZ. (S)Threonine/a, $\alpha-(S)$-diphenylvalinol-derived chiral ionic liquid: an immobilized organocatalyst for asymmetric syn-aldol. Tetrahedron 2011; 67: 1948-54. http://dx.doi.org/10.1016/j.tet.2011.01.017 